\title{
Cyberbullying: The hidden side of college students
}

\author{
Sofia Mateus Francisco ${ }^{\mathrm{a}, *}$, Ana Margarida Veiga Simão ${ }^{\mathrm{a}, 1}$, Paula Costa Ferreira ${ }^{\mathrm{a}, 1}$, \\ Maria José das Dores Martins ${ }^{\mathrm{b}, 2}$
}

${ }^{a}$ Faculty of Psychology, University of Lisbon, Lisbon, Portugal

${ }^{\mathrm{b}}$ Polytechnic Institute of Portalegre, Portalegre, Portugal

\section{A R T I C L E I N F O}

Article history:

Available online 20 November 2014

\section{Keywords:}

Cyberbullying

Reporting

College students

Coping strategies

Help sources

\begin{abstract}
A B S T R A C T
The purpose of this study was to investigate how university students perceive their involvement in the cyberbullying phenomenon, and its impact on their well-being. Thus, this study presents a preliminary approach of how college students' perceived involvement in acts of cyberbullying can be measured. Firstly, Exploratory Factor Analysis $(N=349)$ revealed a unidimensional structure of the four scales included in the Cyberbullying Inventory for College Students. Then, Item Response Theory $(N=170)$ was used to analyze the unidimensionality of each scale and the interactions between participants and items. Results revealed good item reliability and Cronbach's $\alpha$ for each scale. Results also showed the potential of the instrument and how college students underrated their involvement in acts of cyberbullying. Additionally, aggression types, coping strategies and sources of help to deal with cyberbullying were identified and discussed. Lastly, age, gender and course-related issues were considered in the analysis. Implications for researchers and practitioners are discussed.
\end{abstract}

(c) 2014 Elsevier Ltd. All rights reserved.

\section{Introduction}

School violence is a contemporary topic of discussion and one of the main causes of concern of students and professionals of the educational system. According to the literature, violence in educational settings has increased (Li, 2006), with aggravated consequences for the teaching and learning processes (Glover, Gough, Johnson, \& Cartwright, 2000), as well as the socio-affective development of students (Clarke \& Kiselica, 1997). Furthermore, school is the place where adolescents spend the majority of their time. Therefore, it is a critical arena of social support and academic development. Some of the literature has shown that students in schools with higher levels of bullying perform worse academically.

\footnotetext{
* Corresponding author at: Faculty of Psychology, University of Lisbon, Alameda da Universidade, 1649-013 Lisbon, Portugal. Tel.: +351 966569 961, +351 217943 655; fax: +351217933408.

E-mail addresses: sofia.francisco@campus.ul.pt (S.M. Francisco), amsimao@ psicologia.ulisboa.pt (A.M. Veiga Simão), paula.costa.ferreira@gmail.com (P.C. Ferreira), mariajmartins@mail.esep.ipportalegre.pt (M. J. d. D. Martins).

1 Tel: +351217943 655: fax: +351217933408.

2 Address: Praça do Município, 7300 Portalegre, Portugal. Tel.: +351 245301 500 fax: +351245330 353 .

${ }^{3}$ Text written within the project Cyberbullying. A diagnosis of the situation in Portugal (Reference: PTDC/CPE-CED/108563/2008), funded by FCT, under the Thematic Operational Programme for Competitiveness Factors (COMPETE) and cofinanced by the European Community Fund FEDER. The conclusions and opinions expressed here are the sole responsibility of the authors.
}

(Strøm, Thoresen, Wentzel-Larsen, \& Dyb, 2013). This type of violence affects many children and teenagers, at school and at home with the expansion and development of information and communication technologies (ICT). This insecurity is present at different grade levels, including university contexts and therefore, research involving the different forms of bullying is crucial in order to provide a better understanding of how it occurs, how students can deal with it and ultimately, how it can be prevented.

As ICT have increasingly been incorporated into schools because they foster creative and autonomous ways of communicating and interacting, the risks and dangers associated with them also increase ( $\mathrm{Li}, 2006)$. To specify, the rapid development of ICT (e.g. Internet and cell phones) has created more opportunities for bullies (Li, 2006, 2008) in the sense that the increased use or misuse of these electronic devices among teenagers (Slonje \& Smith, 2008), has originated a new form of bullying (Beran \& Li, 2007), that is, cyberbullying.

Cyberbullying has a considerable impact on the lives of children and teenagers, considering it emerges at the elementary level and continues to higher education (Hinduja \& Patchin, 2009) with increasing frequency and severity in and out of schools ( $\mathrm{Li}$, 2006). In light of these issues and because cyberbullying entails negative psychological and physical consequences that may affect interpersonal relationships (Anderson \& Sturm, 2007), research should focus on the perceptions students have of their involvement in situations of cyberbullying, along with its associated dangers. 
Firstly, this study aims to understand how college students view and report their involvement in situations of cyberbullying. Hence, we present an inventory which could allow us to achieve this objective through the interpretation of its structure. We used Item Response Theory (IRT), which allowed us to calibrate our participants and items on a common scale (DeMars, 2010; Embretson, 1996). This type of measurement presents an analysis of the interactions between people and items, enabling the interpretation of the variables in question. What's more, the interpretations of items in which participants have a higher or lower probability of dominating, have an important diagnostic convenience for our study, along with other group-related ratings, which we consider later.

To complement our first analysis, the present study also explores the dynamics of cyberbullying in order to provide a better understanding of how college students view this phenomena from different perspectives (the roles of the victim, aggressor and observer of victims and/or aggressors). We also consider different aspects that are associated with cyberbullying, such as intimidation and image appropriation that may affect the lives of college students. Moreover, with the analyses presented in this study, we provide insights regarding the means through which cyberbullying occurs (i.e. type of ICT used), as well as the most common types of occurrence in Portuguese college settings.

\section{Review of the literature}

\subsection{From bullying to cyberbullying}

Educational contexts are not free of violence and aggression. This type of violence is generally called bullying, referring to behaviors of abuse of power among peers with the intent of harming others in a prolonged manner (Olweus, 1993). Several authors (Olweus, 1993; Smith \& Brain, 2000) have defined bullying behavior and some of its characteristics. Essentially, there are three important aspects to consider, namely, the intention to physically, psychologically or socially harm the victim, the repeated aggressive behavior over time; and the unbalanced physical, mental and/or social power between the bully and the victim. Currently, with the development of new ICT, bullying has gained another form of expression, which is entitled cyberbullying, a form of bullying carried out through new technologies (David-Ferdon \& Hertz, 2007).

The definition of cyberbullying is not very clear as of yet, but according to Willard $(2005,1)$, cyberbullying consists in being cruel to another person "by sending or posting harmful material or engaging in other forms of social aggression using the Internet and other digital technologies". Thus, cyberbullying involves the use of ICT as a support for deliberate, repeated and hostile behavior developed by an individual or group, with the intent of harming others (Belsey, 2005). Hinduja and Patchin $(2009,5)$ presented a very simple definition of cyberbullying which resumes all its main characteristics, that is: "cyberbullying is willful and repeated harm inflicted through the use of computers, cell phones and other electronic devices". Hence, cyberbullying can be considered a bullying problem that takes place in new territory (Li, 2006). Research has shown that the most common cause of cyberbullying appears to be relationship problems (Glover et al., 2000; Spears, Slee, Owens, \& Johnson, 2009). Nonetheless, although disruptions in real-world relationships seem to be the source of cyberbullying, the latter also has an impact on relationships. This problem has been presented as a cycle, since relationships cannot occur without interference from a social technological world (Spears et al., 2009).

With the electronic market targeting children from an early age, there have been reports of cyberbullying at the elementary level (Hinduja \& Patchin, 2009). However, it occurs most frequently during the transition years between primary and secondary school (Price \& Dalgleish, 2010). According to Hinduja and Patchin (2009), cyberbullying is merely schoolyard bullying that has become a more pernicious form of bullying which emerged due to the proliferation of information and communications technology (Hinduja \& Patchin, 2010). Cyberbullying can be seen as a continuation of bullying, however, this phenomenon is not limited only to this. It is of a more complex nature. Thus, its typology is varied and multifaceted (Amado, Matos, Pessoa, \& Jäger, 2009). Based on Willard's typology (2005) of eight different types of cyberbullying, it is possible to identify two distinct forms. The first is a more direct form of aggression (e.g., Flaming, Harassment, Denigration, Outing), while the second is more indirect and specific to cyberbullying (e.g. Impersonation). Considering these different forms of cyberbullying and the relation between the type of bullying practiced, as well as gender, research has consistently shown a tendency for boys to be more engaged in direct forms of aggression (e.g., physical and verbal), whereas girls tend to engage more in indirect types of aggression, such as social isolation and intentional exclusion from a group (Olweus, 1993). Indirect types of aggression are more frequent in cyberbullying, where girls outnumber boys (Kowalski \& Limber, 2007). Victims' rates are also higher for girls (Ortega, Elipe, \& Calmaestra, 2009; Ortega, Elipe. Mora-Mérchan, Calmaestra, \& Vega, 2009).

There seems to be a relation between bullying and cyberbullying in the sense that victims of bullying are also more likely to be victims of cyberbullying. Williams and Guerra (2007) studied the association between normative beliefs about face-to-face aggression and cyberbullying. Their results showed that the acceptability of face-to-face aggression was positively related to cyberbullying among adolescents. Nonetheless, this relationship was weaker in comparison to the association between face-to-face aggression and the normative beliefs about such behaviors. Gradinger, Strohmeier, and Spiel (2010) speculated that if cyberbullying is considered a form of bullying with the use of electronic devices, then it must co-occur with bullying and thus, most cyberbullies should also be aggressors (Raskauskas \& Stoltz, 2007). Moreover, bullying victims are also likely to become the aggressor in cyberbullying (Jang, Song, \& Kim, 2014) because it can be a form of retaliation towards their own aggressor (Beran \& Li, 2007). In a recent study (Baroncelli \& Ciucci, 2014), both traditional bullying and cyberbullying were positively correlated with the corresponding form of victimization, suggesting that students could be simultaneously involved in multiple roles.

Additionally, Ortega, Elipe, and Calmaestra (2009) and Ortega, Elipe, Mora-Mérchan, et al. (2009) found that nearly 2 out of 10 students considered themselves victims of some form of bullying, and only 1 in 10 considered themselves victims of cyberbullying. However, there is a higher percentage of students ( 1 in 5 students) that are considered victims of both types of bullying. Often, young individuals cannot be classified solely as the "victim" or the "perpetrator", because they may be a victim, a perpetrator, and/ or an observer on several occasions (Espelage \& Swearer, 2003). Furthermore, compared to non-bullies, bullies have a greater tendency to be cyberbullies. Hence, victims of bullying are also more likely to be victims of cyberbullying. Moreover, cyberbullies are more likely to be victims in cyberspace than those who do not cyberbully (Li, 2006).

Smith et al. (2008) distinguished seven distinct sub-categories according to the way victims are targeted. Thus, the sub categories are: text messages, picture/video clips; phone calls; emails; chat rooms; instant messaging and via websites. More recently, Ellison and Boyd (2013) indicated that cyberbullying is mostly practiced trough the use of social networks, such as Facebook, Twitter, MySpace, You Tube, Google Plus and LinkedIn, which are considered networked communication platforms. Individuals 
participating in these platforms have distinctive profiles that can be comprised of user-supplied content, content provided by other users, and/or system-provided data. What's more, individuals can create a public or semi-public profile, as well as manage social connections that can be viewed and tracked by others. Lastly, individuals can create, consume and interact with streams of content generated and provided by their connections on the network. Despite many sites' restricted access to children, a 2010 peer-reviewed study sponsored by Microsoft Research, found that $19 \%$ of 10 -year-olds, $32 \%$ of 11 -year-olds, and $55 \%$ of 12 -year-olds had Facebook accounts. Furthermore, the data showed that many parents knowingly allowed their children to lie about their age and often helped them do so in order to gain access to agerestricted sites, in violation of those sites' terms of service (Davis, 2012).

Due to the use of these technologies, cyberbullying has some specificities that surpass the boundaries of time, since it is infinitely present in virtual space, and accordingly, also goes beyond the boundaries of personal and physical space (Amado et al. 2009). Cyberbullying crosses geographic boundaries, so it can spread much faster and more broadly (Li, 2008). Like bullying, cyberbullying is grounded on an imbalance of power, but in cyberbullying this imbalance also refers to skills and advantages in mastering technology (Amado et al., 2009; Dooley, Pyżalski, \& Cross, 2009), thus the aggressor doesn't need to be physically stronger or bigger than the victim (Li, 2008). However, Wolak, Mitchell, and Finkelhor (2006) referred that cyberbullying victims are also in a position of power because they can easily terminate the negative interactions (eg. block the aggressor). This means that cyberspace offers coping tools that are not available offline (Price \& Dalgleish, 2010), making it easier for victims of cyberbullying to escape in comparison with victims of bullying. Nonetheless, there is a different power imbalance present in cyberbullying (Amado et al., 2009) regarding the incapacity of the victim to escape in terms of space and time, since it may occur at any hour of the day and night (Dooley et al., 2009), and in and out of school borders - virtually anywhere. Yet, cyberbullying can be conserved easily (Li, 2008), such as saving emails or messages, which serve as evidence of the aggression.

Moreover, cyberbullying involves "invisibility" (Slonje \& Smith, 2008), making it possible and easy to maintain the aggressor's anonymity (Kowalski \& Limber, 2007) and thus facilitating this type of interaction between peers, acquaintances or strangers. This entails little or no consciousness on the aggressor's behalf regarding the consequences provoked by their actions towards the victims (Slonje \& Smith, 2008). Nonetheless, it seems reasonable to believe that in bullying some bullies may be ashamed or have a guilty conscience because of what they are doing (Roland, 2002). Therefore, the reactions of victims are mediators and modulators of what individuals are capable of doing (Ortega, Elipe, \& Calmaestra, 2009). Furthermore, without this feedback, there are fewer opportunities for empathy, remorse and the intervention of observers (Slonje \& Smith, 2008). In addition, anonymity limits the victim's response to cyberbullying in terms of stopping the aggressive behavior or influencing the likelihood of future acts (David-Ferdon \& Hertz, 2007).

Baroncelli and Ciucci (2014) studied the awareness bullies and cyberbullies have of their own emotions. The authors found that children who engaged in bullying or cyberbullying behaviors did not perceive themselves as deficient in catching emotional cues from others or themselves (the basic processes of emotional intelligence). In addition, they reported they were able to accurately monitor and regulate their emotional states, and consequently, choose the most effective way to attack victims without incurring sanctions. Similarly, cyberbullies did not declare deficits in their basic emotional processes. Rather, they reported that they were able to regulate their emotional processes, which enabled them to act out their cyberbullying behaviors.

Another matter that differentiates cyberbullying from other isolated aggression phenomena is the repetition with which these acts are conducted (like bullying). It is complicated to control the repetition in cyberbullying (Dooley et al., 2009) because repetition refers to the amount of times the message is sent, displayed and seen by another person, regardless of the aggressor's intentions (Slonje \& Smith, 2008). Thus a single act by one perpetrator may be repeated many times by others, and experienced many times by the victim (Slonje, Smith, \& Frisén, 2013). Furthermore, the frequency of aggression in face-to-face bullying is easier to quantify than through electronic means. Therefore, rereading disseminating and visualizing messages, can be considered one act or as part of a cycle of repeated acts (David-Ferdon \& Hertz, 2007).

Comparatively to bullying, these differences seem to add new profile characteristics of perpetrators and victims (Amado et al., 2009). What's more, the consequences of cyberbullying seem to be enlarged (Willard, 2005) because the aggressions can easily and rapidly be disseminated in cyberspace (Belsey, 2005), occurring anytime, anywhere (Belsey, 2005; David-Ferdon \& Hertz, 2007). Therefore, these consequences are repeated and long-lasting (Amado et al., 2009).

Research has shown evidence of the victims' suffering, including feelings of sadness, anger, fear and loss of hope - feelings that influence both concentration and academic achievement (Beran \& Li, 2005), resulting in learning problems and absenteeism (Amado et al., 2009). Langos (2013) found that emotional harm in the context of cyberbullying refers to anxiety, distress, fear, grief, anger or humiliation, and extends to more severe forms of harm, such as protracted psychological injury and long-term psychiatric harm. Considering that some types of cyberbullying are more harmful than others (Langos, 2014), its consequences can result in a continuum of effects, and therefore, attentions must focus on the severity of the incident within the context in which it occurs and the circumstances surrounding it (Hinduja \& Patchin, 2010).

Considering cyberbullying is a phenomena which individuals must learn to deal with, it is crucial for research to focus on the coping strategies that are associated with it. Jacobs, Dehue, Völlink, and Lechner (2014) studied the determinants related to effective and ineffective coping strategies. Thus, for ineffective coping, the largest category found was associated with environmental determinants, followed by psychological determinants. Then, to a much lesser extent, personal and behavioral determinants, and, finally, social demographic determinants (i.e. younger age) were also found to be associated with ineffective coping. Among the most relevant predictors were psychological (i.e. a predisposition toward passive or emotion-focused coping, lack of knowledge of coping strategies), personal and behavioral (i.e. poor social skills, limited conflict resolution skills, poor communication styles, previous victimization, isolation), and environmental determinants (i.e. low monitoring/supervision/control in school, at home). On the other hand, for improvement in coping strategies, the category to which most determinants were assigned was the category of psychological determinants, followed equally by environmental determinants, then personal and behavioral determinants, and, lastly, social demographic determinants. Among the most relevant predictors for improvement were psychological (i.e. positive outcome expectations, high self-esteem and self-efficacy, knowledge how to report cyberbullying, high assertiveness), personal and behavioral (i.e. good mental health state, strong social skills, active in social relationships), and environmental determinants (i.e. social support from various sources, including parents, high quality support, positive social influence). 


\subsection{Cyberbullying in higher education}

Even though there have been great advances in cyber aggression research, much of this research is conducted among adolescents, with few investigations on young adults, between the ages of 18 and 25 (Wright \& Li, 2013).

In Portugal, cyberbullying has only been studied with small samples and with the main purpose of diagnosing the problem in schools for future interventions (Amado et al., 2009). Bullying and cyberbullying studies have focused mainly on adolescence because of the theory that aggression reaches its peak in adolescence and begins to decline thereafter. Also because of the potential reasons for the high frequency of school violence that are possibly related to the sudden and drastic biological and social changes experienced by adolescents (Li, 2007). However, these phenomena are not only present in adolescence, they also occur during the university years with young adults (Akbulut \& Eristi, 2011; Azevedo, 2013; Dilmaç, 2009; Finn, 2004; Francisco, 2012; Kraft \& Wang, 2010; Souza, 2011; Walker, Sockman, \& Koehn, 2011).

Finn (2004) mentioned that what may lead to cyberbullying, is the easy access the university population has to the Internet and the wireless network in universities and faculties (in student residencies, libraries, etc.). In Finn's study, $10-15 \%$ of 339 students from New Hampshire University had received e-mails or instant messages related to online harassment from strangers, acquaintances, or a significant other. No significant differences were found in age, gender, race, class standing, or residence in e-mail or instant messages harassment variables. Akbulut and Eristi (2011) investigated the extension of cyberbullying and victimization among Turkish university students at a state college of education. Victims received emails or instant messages $(81.1 \%)$ with religious or political content $(63.9 \%)$, invitations to social applications including gossip or inappropriate chat $(63.5 \%)$, cursing or slang language while using instant messaging programs (61.8\%), obscene emails (61.8\%), addressees with hidden identities (61.7\%), and unwanted content without the receiver's consent (61.4\%).

Dilmaç (2009) found that men reported more cyberbullying behaviors than women, but that women were more frequently exposed to cyberbullying situations than men (with a percentage of victims and aggressor-victims larger in women). According to this author, $22.5 \%$ of students had cyberbullied others at least once and 55.3\% reported having been cyberbullied at least once. The percentage of victims was larger than the aggressors, which is consistent with other authors (Raskauskas \& Stoltz, 2007). Kraft and Wang (2010) conducted a study with college students from New Jersey, and discovered that $10 \%$ had already been victims of cyberbullying and cyberstalking. Students below 25 years of age experienced more cyberbullying than older students. These authors also found that there is a risk factor regarding the continuity between having been a victim in high school and being a victim in college. Lastly, Walker et al. (2011) discovered that $54 \%$ of college students knew someone that had been a victim of cyberbullying. Furthermore, $11 \%$ of these students had been victims in college and the more prevalent technologies reported were Facebook (64\%), cell phones (43\%) and instant messages (43\%). Accordingly, $50 \%$ of the aggressors were classmates of the victims, $57 \%$ did not belong to the university and $43 \%$ of the victims did not know the aggressor. Moreover, $71 \%$ of the students mentioned telling the incident to parents or other adults.

Cyberbullying behaviors are becoming more visible in high school and college-aged populations (Hinduja \& Patchin, 2009), and given that the high school population is the most studied, there is a need for research to focus on college students.

\subsection{Reporting cyberbullying}

Some studies have shown that often students do not disclose bullying incidents they have either experienced or witnessed (DeLara, 2008; Garbarino \& DeLara, 2002; Mishna \& Alaggio, 2005; Pepler, Jiang, Craig, \& Connolly, 2008). Research has also found that high school students in particular, may even be instructed by adults to ignore bullying (Yoon, Bauman, Choi, \& Hutchinson, 2011). DeLara (2012) proposed that cyberbullying prevention programs often fail to have a greater impact because most research focuses on the perceptions of adults (e.g. parents and teachers), rather than on the students' perspectives. Other authors (Vannucci, Nocentini, Mazzoni, \& Menesini, 2012) found that false memories of hostile situations (memory distortions) were positively associated with cyberbullying.

We argue that the same may occur when students are confronted with incidents of cyberbullying. That is, students may feel reluctant to or even have difficulty in disclosing incidents of cyberbullying, even when responding to questionnaires and independently of being in high school or college. DeLara (2012) found through the Grounded Theory approach that many students did not report incidents of bullying because they felt helpless, ashamed, self-reliant, worried about the reactions of adults, among other reasons. The author suggested that research should focus on understanding bullying from the students' perspectives so as to reduce its incidence and encourage its reporting. Also, Vannucci et al. (2012) suggested that research could focus more on students' attributions and memory bias in order to approach the phenomenon of cyberbullying. In agreement with these recommendations, but focusing specifically on cyberbullying, this study focused on understanding how college students view and repot their involvement in this phenomenon.

\subsection{Current study}

In light of the theoretical findings and suggestions we have presented, we proposed to develop a new measure and to understand how college students view themselves as participants in situations of cyberbullying. Specifically, we wanted to know how college students report their involvement as victims, aggressors and observers of the victims and/or the aggressors and whether they are giving accurate accounts of this involvement. Thus, we hypothesize that college students underrate their level of involvement in situations of cyberbullying, regardless of whether they are the victim, the aggressor or an observer of either the victim and/or the aggressor.

Then, from the results gathered, we present an analysis of how cyberbullying is acknowledged by and occurs among college students. Specifically, we intend to know the frequency and types of cyberbullying that are most commonly reported by university students. Also, because some studies have suggested that research should focus on examining different behaviors across different technologies and how these may affect students' perceptions (Talwar, Gomez-Garibello, \& Shariff, 2014), we decided to identify the technological means most used in these practices, as well as the coping strategies used by victims and observers to deal with this phenomenon. Lastly, we focused on identifying who students turn to when cyberbullying occurs, and when they remember cyberbullying occurring. Accordingly, we include analyses regarding issues of gender, age and course differences.

\section{Method}

\subsection{Participants}

Initially, we had 12 students participate in an interview that lead to the construction of the inventory. These students were 
between 19 and 24 years of age. Later, we used a convenience sample of 519 undergraduate college students $(N=349$ in our exploratory study and $N=170$ in our IRT analysis). From the University of Lisbon, students $(N=349)$ attended the Psychology (43.2\%) and Science Education (24.1\%) courses, whereas students $(N=170)$ from the Polytechnic Institute of Portalegre attended Sociocultural Animation (3.1\%), Basic Education (4.0\%), Nursing (11.6\%), Journalism (9.1\%) and Social Service (5.0\%) courses. The sample consisted of 402 female participants (77.6\%) and 116 male participants (22.4\%). Regarding age, 59.9\% of individuals were 20 years of age or less, $25.9 \%$ were between 21 and 23 years of age, $4.4 \%$ were between 24 and 26 , and lastly, 9.7\% were over 26 . Considering the university years participants were attending, 216 (41.6\%) were in their first year, 127 (24.5\%) in their second year and 176 (33.9\%) in their third year of the course.

\subsection{Instrument}

The inventory begins with an introduction about how ICT can be used to maltreat others, asking students to remember the last experience they had. The Cyberbullying Inventory for College Students (CICS) is an inventory about the type and degree of involvement in cyberbullying. The final version of the inventory includes socio-demographic items and 42 close-ended questions. It is comprised of 4 scales, including a scale for victims (9 items), for aggressors ( 8 items), for observers of the victim (9 items), and for observers of the aggressor ( 9 items). The answer options for these scales are never, sometimes and many times (e.g. Items of each perspectives: "They threatened me"; "I spread rumors about someone's life"; "They used someone's image without authorization"). The CICS also includes questions regarding the level of education of the last occurrence (e.g. primary, secondary, or higher education) and whether the victim knows the aggressor and identifies him/her (e.g. boy, girl, mixed group). Also, two of the items require a response from all participants and inquire about who can help deal with these situations and which coping strategies are used. Furthermore, the inventory also asks about the digital media used (e.g. computer and mobile phone; Facebook, $H i 5$, Messenger), the emotions involved and the motives of the aggressor, as well as, the coping strategies used by victims and observers.

\subsection{Procedure}

\subsubsection{Development of the CICS}

Self-report measures are the most commonly used in research because they provide information about subjective experiences (Graham, Bellmore, \& Juvonen, 2003), allowing victims, perpetrators and observers to expose their experiences about this phenomenon. With this in mind, we interviewed 12 students with the objective of constructing the CICS. These semi-structured interviews allowed us to understand the perspectives of students and their answers helped us construct the final version of the inventory. The items were initially developed according to students responses and covered some of the issues presented in the definitions and characterizations of cyberbullying provided by the literature (Belsey, 2005; Hinduja \& Patchin, 2009; Li, 2006; Willard, 2005). Specifically, we tried to include items that covered more direct forms of aggression which are typical of traditional bullying, such as intimidation, as well as indirect forms of harassment, which are specific to cyberbullying, such as image appropriation. The facial and content validity of the CICS were tested with five undergraduate students. This procedure included think aloud sessions that enabled spontaneous commentaries and suggestions from the students, trying to eliminate possible ambiguities in the interpretation of the items.

\subsubsection{Preliminary testing of the CICS}

After obtaining the approval of the university's board of directors, we asked students to fill in the inventory during class. It took students about 15-20 min to complete it. The objectives, as well as all of the ethical guidelines (volunteering and anonymity) of the study were explained to all of the students. Once we gathered the data, we performed an Exploratory Factor Analysis (EFA) with IBM SPSS 20.0 and FACTOR 9.20 so as to ascertain the internal structure of the scales regarding the number of factors they would yield. In particular, we wanted to understand whether distinct components would hold for various aspects regarding cyberbullying, such as intimidation and image appropriation, or whether single unidimensional scales of cyberbullying would make up the CICS.

\subsubsection{Item Response Theory approach}

After reaching an interpretable structure of the four scales of the CICS, which we describe in the results section, we applied them to a second sample of 170 students. As in previous studies (Ferreira, Almeida, \& Prieto, 2011, 2012), we opted for a type of statistical analysis that is distinct from the Classical Test Theory for this second analysis. The IRT would allow us to better understand the ratings of college students regarding their involvement in situations of cyberbullying. Specifically, we used Rasch analysis with the Winsteps program in order to assess the unidimensionality of the instrument, as well as to understand how the students had rated their involvement in situations of cyberbullying. This analysis enabled us to estimate the students' score on a one-dimensional logit scale, as well as evaluate the properties of the scales included in the CICS. We adopted the Rasch polytomous methodology to analyze the instrument and the students' ratings. To specify, we used the Partial Credit Model (PCM), which is an extension of the Rasch model for polytomous items (Rasch, 1980). The PCM for linear measures of observations of ordinal scales is $\log \left(P_{n i k} / P_{n i(k-1)}\right) /$ $\Theta_{n}-\beta_{i} t_{k i}$, where $P_{n i k}$ is the probability that person $n$ upon encountering item $i$ responds in category $k$. In accordance, while $P_{n i(k-1)}$ is the probability that the response is in category $k-1, \Theta_{n}$ is the ability of person $n, \beta_{i}$ is the difficulty (or as proposed in this study, the level of rating) of item $i$, and $t_{k i}$ is the step calibration in the rating scale threshold, which is defined as the position equivalent to the equal probability of responses in adjacent categories $k-1$ and $k$ (Wright \& Masters, 1982). In this study for instance, categories alter from 1 to 3 for involvement in situations of cyberbullying. The higher score (3) constitutes overrating (always), whereas the lower score (1) constitutes underrating (never).

All items were examined to understand whether they fit the model $(p<.01)$ or whether there were items with extreme infit and outfit mean square residuals. Specifically, we considered removing infit standardized mean squares higher than 1.4 and outfit standardized mean-squares higher than 2.0, as suggested in the literature (Bond \& Fox, 2007).

\section{Results}

\subsection{Cyberbullying Inventory for College Students - exploratory evidence}

We used IBM SPSS 22.0 and FACTOR 9.2 to interpret the internal structure of the four scales. Table 1 shows the correlations among all variables for each scale, as well as the descriptive statistics.

We used polychoric correlations, as suggested in the literature, when univariate distributions of ordinal items are asymmetric for polytomous items (Brown, 2006; Muthén \& Kaplan, 1985, 1992). We tested the data with the Kaiser-Meyer-Olkin (KMO) and the Bartlett's Test of Sphericity to understand its underlying structure. 
The KMO measure of sampling adequacy was a good (i.e. .84, .87,.88, .83 , respectively), while the Bartlett Sphericity was $\chi^{2}(36)=1385.3$ $(p<.001), \chi^{2}(28)=2154.8(p<.001), \chi^{2}(36)=2080.6(p<.001)$ and $\chi^{2}(36)=2375.9(p<.001)$, demonstrating that the variables were suitable for factor analyses. Furthermore, we tested for multivariate normality. As Bollen and Long indicate (1993), if Mardia's coefficient is lower than $P(P+2)$, where $P$ is the number of observed variables, then there is multivariate normality. In this study, 9 observed variables were used in all scales except the aggressors' scale (with 8 items) with a Mardia's coefficient for skewness of $136>9(9+2)=99$ and for kurtosis of $395>9(9+2)=99$ for the victims' scale, a Mardia's coefficient for skewness of $48<9(9+2)=99$ and for kurtosis of $232>9(9+2)=99$ for the observers of the victims' scale and a Mardia's coefficient for skewness of $212>9(9+2)=99$ and for kurtosis of $578>9(9+2)=99$ for the observers of the aggressors scale. In the aggressors' scale we had 8 observed variables with a Mardia's coefficient for skewness of $182>8(8+2)=80$ and for kurtosis of $483>8(8+2)=80$. Hence, considering our skewness and kurtosis values, we used Unweighted Least Squares (ULS) as the method for factor extraction, which is an estimation method that is not dependent on distributional assumptions (Joreskog, 1977). In order to retain the appropriate number of factors, we applied various factor retention criteria, namely, Velicer's MAP test and Horn Parallel analyses. According to the literature, these analyses perform optimally in determining the number of factors to extract (Bandalos \& Finney, 2010). By using different

Table 1

Item descriptive statistics, Exploratory Factor Analysis parameters, reliability and correlations of the CICS.

\begin{tabular}{|c|c|c|c|c|c|c|c|c|c|c|}
\hline \multirow[t]{2}{*}{ Variables } & \multirow[t]{2}{*}{ Structure coefficients } & \multirow[t]{2}{*}{$\operatorname{Mean}(S D)$} & \multicolumn{8}{|c|}{ Correlations } \\
\hline & & & 1 & 2 & 3 & 4 & 5 & 6 & 7 & 8 \\
\hline \multicolumn{11}{|l|}{ Victims' scale } \\
\hline Item 1 & .79 & $1.13(.35)$ & & & & & & & & \\
\hline Item 2 & .74 & $1.07(.28)$ & .53 & & & & & & & \\
\hline Item 3 & .91 & $1.19(.46)$ & .72 & .67 & & & & & & \\
\hline Item 4 & .77 & $1.08(.28)$ & .53 & .59 & .71 & & & & & \\
\hline Item 5 & .86 & $1.18(.45)$ & .73 & .65 & .84 & .54 & & & & \\
\hline Item 6 & .91 & $1.25(.50)$ & .80 & .63 & .81 & .66 & .89 & & & \\
\hline Item 7 & .84 & $1.13(.38)$ & .70 & .68 & .73 & .63 & .72 & .80 & & \\
\hline Item 8 & .86 & $1.09(.33)$ & .64 & .67 & .85 & .69 & .70 & .71 & .74 & \\
\hline Item 9 & .69 & $1.07(.26)$ & .55 & .54 & .55 & .79 & .55 & .57 & .52 & .59 \\
\hline Eigenvalues & 6.15 & & & & & & & & & \\
\hline \% Explained variance & $72 \%$ & & & & & & & & & \\
\hline Cronbach's alpha & .96 & & & & & & & & & \\
\hline \multicolumn{11}{|l|}{ Aggressors' scale } \\
\hline Item 2 & .81 & $1.00(.05)$ & & & & & & & & \\
\hline Item 3 & .95 & $1.01(.10)$ & & .76 & & & & & & \\
\hline Item 4 & .84 & $1.03(.17)$ & & .82 & .80 & & & & & \\
\hline Item 5 & .97 & $1.06(.24)$ & & .77 & .94 & .82 & & & & \\
\hline Item 6 & .94 & $1.05(.24)$ & & .71 & .93 & .78 & .96 & & & \\
\hline Item 7 & .88 & $1.02(.13)$ & & .71 & .84 & .70 & .85 & .83 & & \\
\hline Item 8 & .93 & $1.01(.10)$ & & .73 & .91 & .72 & .89 & .88 & .91 & \\
\hline Item 9 & .91 & $1.01(.12)$ & & .77 & .84 & .81 & .87 & .87 & .81 & .83 \\
\hline Eigenvalues & 6.80 & & & & & & & & & \\
\hline \% Explained variance & $85 \%$ & & & & & & & & & \\
\hline Cronbach's alpha & .98 & & & & & & & & & \\
\hline \multicolumn{11}{|c|}{ Observers of victims' scale } \\
\hline Item 1 & .75 & $1.23(.51)$ & & & & & & & & \\
\hline Item 2 & .73 & $1.21(.52)$ & .45 & & & & & & & \\
\hline Item 3 & .92 & $1.48(.73)$ & .66 & .68 & & & & & & \\
\hline Item 4 & .74 & $1.21(.54)$ & .54 & .56 & .73 & & & & & \\
\hline Item 5 & .92 & $1.53(.77)$ & .73 & .62 & .86 & .61 & & & & \\
\hline Item 6 & .88 & $1.49(.75)$ & .77 & .56 & .84 & .64 & .94 & & & \\
\hline Item 7 & .90 & $1.38(.68)$ & .74 & .70 & .80 & .55 & .82 & .78 & & \\
\hline Item 8 & .92 & $1.34(.66)$ & .71 & .73 & .84 & .66 & .80 & .74 & .90 & \\
\hline Item 9 & .88 & $1.35(.68)$ & .56 & .72 & .78 & .83 & .80 & .70 & .77 & .83 \\
\hline Eigenvalues & 6.83 & & & & & & & & & \\
\hline \% Explained variance & $75 \%$ & & & & & & & & & \\
\hline Cronbach's alpha & .97 & & & & & & & & & \\
\hline \multicolumn{11}{|c|}{ Observers of aggressors' scale } \\
\hline Item 1 & .83 & $1.09(.32)$ & & & & & & & & \\
\hline Item 2 & .82 & $1.06(.29)$ & .73 & & & & & & & \\
\hline Item 3 & .96 & $1.20(.52)$ & .80 & .76 & & & & & & \\
\hline Item 4 & .85 & $1.09(.39)$ & .73 & .82 & .80 & & & & & \\
\hline Item 5 & .97 & $1.23(.54)$ & .82 & .77 & .94 & .82 & & & & \\
\hline Item 6 & .95 & $1.23(.53)$ & .82 & .71 & .93 & .78 & .96 & & & \\
\hline Item 7 & .88 & $1.11(.39)$ & .72 & .71 & .84 & .70 & .85 & .83 & & \\
\hline Item 8 & .93 & $1.14(.45)$ & .79 & .73 & .91 & .72 & .89 & .88 & .91 & \\
\hline Item 9 & .89 & $1.12(.42)$ & .60 & .77 & .84 & .81 & .87 & .87 & .81 & .83 \\
\hline Eigenvalues & 7.33 & & & & & & & & & \\
\hline \% Explained variance & $83 \%$ & & & & & & & & & \\
\hline Cronbach's alpha & .98 & & & & & & & & & \\
\hline
\end{tabular}


methods of extraction, we aimed to propose an approximation to a simple interpretable structure (see Table 2). We considered all items with structure coefficients values above .30 (Bandalos \& Finney, 2010; Ford, MacCallum, \& Tait, 1986). In accordance with the different retention criteria, one factor was obtained for the victims' scale (with $72 \%$ of explained variance), the observers of the victims' scale (with $75 \%$ of explained variance) and for the observers of the aggressors' scale (with $83 \%$ of explained variance). However, in the aggressors' scale, item 1 presented loadings below .32 on three separate components. We removed item 1 and reran the analysis, hence, obtaining a unidimensional structure of the aggressors' scale with $85 \%$ of explained variance. This preliminary study of the four scales included in the CICS suggested a unidimensional structure of all four scales (victims: $\alpha=.96$, aggressors: $\alpha=.98$, observers of victims: $\alpha=.97$ and observers of aggressors: $\alpha=.98$ ), with good reliability scores according to the psychometric literature (Nunnally, 1978). What's more, the values of goodness-of-fit (victims: $G F I=.99$, aggressors: $G F I=1.00$, observers of victims: $G F I=.99$, observers of aggressors: $G F I=1.00)$, residuals statistics $(R M S R=.06$, $.03, .06, .04$, respectively) were also good in accordance with the literature (McDonald, 1999; Nunnally, 1978; Velicer, 1976).

\subsection{Measuring the perceived level of involvement in situations of cyberbullying with the Item Response Theory approach}

We examined the reports of 170 college students' involvement in situations of cyberbullying with the IRT approach in order to test the unidimensional structure of the scales included in the CICS and in order to understand whether participants underrated this involvement. In the victims scale and in the observers of victims' scale none of the items showed an infit/outfit higher than 1.5 , as well as $z$ statistic higher than 2.00. In the aggressors' scale, item 4 revealed, an infit/outfit higher than 1.5 , and $z$ statistic higher than 2.00. In the observers of the aggressors' scale, items 2, 4 and 9 revealed an infit/outfit higher than 1.5 , and $z$ statistic higher than 2.00. Therefore, we removed these items and reran the analysis for these two scales. For all of the scales, we also present possible models without participants with an infit/outfit higher than 1.5 , as well as $z$ statistic than 2.00 in order to see how the instruments would respond (see Table 3 ).

In the victims' scale item 3 ("They spread rumors about my life.") was the easiest item to report with a reported/difficulty level of $-1.10 \log$, whereas the most difficult to report was item 9 ("They used my image without authorization.") with a reported/difficulty level of $2.48 \mathrm{log}$. The distribution revealed a large range of difficulty $(-1.10<D i<2.48)$. In the aggressors' scale item 5 ("I made fun of someone.") was the easiest item to report with a reported/ difficulty level of $-2.78 \mathrm{log}$, whereas the most difficult to report was item 9 ("I used someone's image without authorization.") with a reported/difficulty level of $2.15 \log$. The distribution revealed a large range of difficulty $(-2.78<D i<2.15)$. In the observers of the victims' scale item 5 ("Someone made fun of them.") was the easiest item to report with a reported/difficulty level of $-1.09 \mathrm{log}$, whereas the most difficult to report was item 4 ("Someone
Table 3

IRT parameters of the CICS.

\begin{tabular}{|c|c|c|c|}
\hline Model & $\alpha$ & Item separation reliability & Person separation reliability \\
\hline \multicolumn{4}{|c|}{ Victims' scale } \\
\hline Model $1^{\mathrm{a}}$ & .86 & .91 & .60 \\
\hline Model $2^{\mathrm{b}}$ & .88 & .90 & .63 \\
\hline \multicolumn{4}{|c|}{ Aggressors' scale } \\
\hline Model $1^{\mathrm{a}}$ & .82 & .78 & .55 \\
\hline Model $3^{\mathrm{b}}$ & .72 & .87 & .55 \\
\hline Model $2^{\mathrm{c}}$ & .79 & .82 & .48 \\
\hline Model $4^{\mathrm{d}}$ & .72 & .88 & .53 \\
\hline \multicolumn{4}{|c|}{ Observers of victims' scale } \\
\hline Model $1^{\mathrm{a}}$ & .91 & .94 & .75 \\
\hline Model $2^{\mathrm{b}}$ & .93 & .95 & .79 \\
\hline \multicolumn{4}{|c|}{ Observers of aggressors' scale } \\
\hline Model $1^{\mathrm{a}}$ & .92 & .91 & .76 \\
\hline Model $3^{\mathrm{b}}$ & .92 & .93 & .81 \\
\hline Model $2^{\mathrm{c}}$ & .94 & .85 & .83 \\
\hline Model $4^{\mathrm{d}}$ & .95 & .87 & .85 \\
\hline
\end{tabular}

${ }^{a}$ Model with all participants and all items.

b Model without participants with high infit/outfit values.

c Model without items with high infit/outfit values.

d Model without participants and items with high infit/outfit values.

pretended to be them.") with a reported/difficulty level of $1.28 \mathrm{log}$. The distribution revealed a moderate range of difficulty $(-1.09<D i<1.28)$. In the observers of the aggressors' scale item 5 ("They made fun of someone.") was the easiest item to report with a reported/difficulty level of $-1.68 \mathrm{log}$, whereas the most difficult to report were items 2 and 8 ("They harassed someone with sexual content." and "They revealed data about someone's private life.") with a reported/difficulty level of $1.49 \mathrm{log}$. The distribution revealed a moderate range of difficulty $(-1.68<D i<1.49)$.

We also considered other reliability indicators from the Rasch measures for involvement in cyberbullying such as, Cronbach's alpha, Person Separation Reliability and the Item Separation Reliability. The Person Separation Reliability shows the proportion of the sample variance which is not explained by the measure error, while the Item Separation Reliability indicates the percentage of item variance that is not explained by the measurement error (Smith, 2001). Table 3 shows the Cronbach's $\alpha$, the Person Separation Reliability and the Item Separation Reliability for all the scales. These scores indicate good internal consistency/reliability independently of removing participants and items with infit/ outfit values higher than 1.5, and $z$ statistic values higher than 2.00 (Fox \& Jones, 1998). The values for Person Separation Reliability in each scale, along with the difficulty indicators, reveal that these students may have had difficulty in responding to all of the items and underrated their involvement in situations of cyberbullying, thus confirming our first hypothesis.

\subsection{Dynamics of cyberbullying in college students and their perceived form of involvement}

After testing the underlying structure of the four scales presented and having examined that college students underrated their

Table 2

Proposed unidimensional EFA model parameters of the CICS inventory.

\begin{tabular}{|c|c|c|c|c|c|c|}
\hline \multirow[t]{2}{*}{ Proposed EFA models ${ }^{\mathrm{a}}$} & \multicolumn{2}{|l|}{ Mardia's coefficient } & \multirow[t]{2}{*}{ Kaiser-Meyer-Olkin } & \multirow[t]{2}{*}{ Bartlett Sphericity } & \multirow[t]{2}{*}{ GFI } & \multirow[t]{2}{*}{ RMSR } \\
\hline & $S$ & $K$ & & & & \\
\hline Victims' scale & $136>9(9+2)=99$ & $395>9(9+2)=99$ & .84 & $\chi_{36}^{2}=1385.3(p<.001)$ & .99 & .06 \\
\hline Aggressors' scale & $182>8(8+2)=80$ & $483>8(8+2)=80$ & .87 & $\chi_{28}^{2}=2154.8(p<.001)$ & 1.00 & .03 \\
\hline Observers of victims' scale & $48>9(9+2)=99$ & $232>9(9+2)=99$ & .88 & $\chi_{36}^{2}=2080.6(p<.001)$ & .99 & .06 \\
\hline Observers of aggressors' scale & $212>9(9+2)=99$ & $578>9(9+2)=99$ & .83 & $\chi_{36}^{2}=2375.9(p<.001)$ & 1.00 & .04 \\
\hline
\end{tabular}

\footnotetext{
a Velicer's Minimum Partial Test used. Horn Parallel Analyses presented same values.
} 
level of involvement in situations of cyberbullying, we present a detailed analysis of the dynamics of cyberbullying (including parameters such as age, gender and year of course) in college students and their perceived form of involvement with the use of frequencies and non-parametric tests (e.g. the Mann-Whitney tests and the Kruskal Wallis test).

\subsubsection{Victims' scale}

In accordance with some of the theoretical issues presented previously, we decided to provide a detailed analysis considering two main aspects of cyberbullying in the victims' scale, namely acts of intimidation and image appropriation. As seen in the theoretical section, intimidation involves acts that are quite similar to those practiced in the context of bullying, such as threatening, harassing, making fun, insulting and spreading rumors (among others). Image appropriation is more specific of cyberbullying, because it involves the identity and/or image of the victim. Considering the items covered these issues, which were presented in the definitions and characterizations of cyberbullying provided by the literature (Belsey, 2005; Hinduja \& Patchin, 2009; Li, 2006; Willard, 2005), we were interested in analyzing the items individually, and these two aspects separately.

In this study, we found 145 (27.94\%) participant victims of cyberbullying ( 143 victims of intimidation and 48 victims of image appropriation), $72.2 \%$ of which were female victims. The most frequent aggressions (see Table 4) reported were: "They insulted me" (73.7\%), followed by "They spread rumors about my life" (59.3\%), "They made fun of me" (55.8\%) and "They threatened me" (46.9\%). From the victims of Intimidation, 28.9\% reported they did not know who the aggressor was, although this type of harassment was more frequently perpetrated by a mixed group (29.3\%), followed by single boys (26.0\%), and by single girls (17.1\%). It is interesting to see the difference between the groups, in comparison to individual situations, verifying that girls in groups (10.6\%) were more likely to harm others than boys in groups (1.6\%). Image Appropriation was more frequent in boys individually and the mixed group (both $25.6 \%$ ), followed by girls individually (18.6\%), and group of girls (7\%). Nonetheless, a great percentage (33.3\%) of students did not know who the aggressor was. This last percentage is similar to one of the cyberbullying specificities - anonymity, and in this case, was more frequent in image appropriation (33.3\%) than in intimidation (28.9\%). The same tendency regarding the behavior of groups was found for image appropriation, with a higher percentage in the group of girls (7\%), and no aggressions perpetrated by the group of boys. The percentage of aggressors as classmates of victims was similar in acts of intimidation and image appropriation (53.2\% and 55\%).

If we consider the unidimensional structure of the victims' scale, the last aggression occurred mainly in secondary education (48.3\%), then in higher education (34.5\%), and lastly in primary education (26.2\%). If we examine acts of intimidation and image appropriation separately, the last act of intimidation occurred mainly in secondary education (47.6\%), then in higher education (33.6\%), and lastly in primary education (25.9\%). Regarding acts of image appropriation, the aggressions had a different distribution: $52.1 \%$ in secondary, $31.3 \%$ in primary, and $22.9 \%$ in higher education. Thus, the distribution varies according to the two different aspects.

Regarding the technologies used, acts of intimidation and image appropriation had similar frequencies of computer use $(68.5 \%$ and $72.9 \%$ ), and use of mobile phones (42\% and 37.5\%). For acts of intimidation, the preferred methods reported were SMS/MMS (35\%), Facebook (30.1\%), Messenger (25.9\%), Hi5 (22.4\%), while Messenger (37.5\%), Hi5 (35.4\%), SMS/MMS (29.2\%), and Facebook (22.9\%) were mainly used for image appropriation.

Table 5 shows the different types of technology through which victims were offended, considering the level of education the aggression took place.

Victims from primary education refer that the main technologies used were SMS/MMS, Hi5 and Messenger. In the victims from secondary education, the tendency is the same regarding technologies, but the percentages change: SMS/MMS, Messenger, Hi5 and Facebook. In higher education, the cyberbullying escalades through Facebook, continues occurring through SMS/MMS, and increases in Blogs.

It is important to refer that the primary education in Portugal is comprised of three cycles, encompassing ages between $6-10,11$ 12 , and 13-15 years of age. The percentage of aggressions through Facebook and Youtube coincide with the beginning of these technologies in Portugal, therefore, these respondents were most likely in the last cycle of primary education. The most common feelings related with acts of intimidation and image appropriation were: insecurity (48.3\%; 64.6\%), anger (48.3\%; 58.3\%), concern (40.6\%; $52.1 \%$ ), sadness (36.4\%; 50\%), embarrassment (31.5\%; $43.8 \%)$, and pride $(30.1 \%, 35.4 \%)$.

Furthermore, $74.6 \%$ of victims of acts of intimidation and $75 \%$ of the victims of acts of image appropriation tried to prevent the continuation of the situation by "confronting the aggressor"; "avoiding contact with the aggressor"; "excluding the aggressor from the social network" and "stopping answering anonymous calls" (see Table 6).

Table 4

Types of aggression experienced by victims, committed by aggressors and observed by observers.

\begin{tabular}{|c|c|c|c|c|c|c|}
\hline \multirow[t]{2}{*}{ Items } & \multicolumn{3}{|c|}{ Victims } & \multirow{2}{*}{$\begin{array}{l}\% \\
\text { Aggressors }\end{array}$} & \multirow{2}{*}{$\begin{array}{l}\% \text { Observers of } \\
\text { victims }\end{array}$} & \multirow{2}{*}{$\begin{array}{l}\text { \% Observers of } \\
\text { aggressors }\end{array}$} \\
\hline & $\%$ & $\begin{array}{l}\text { Acts of } \\
\text { intimidation }\end{array}$ & $\begin{array}{l}\text { Acts of image } \\
\text { appropriation }\end{array}$ & & & \\
\hline Threatening someone $\mathrm{e}^{\mathrm{a}}$ & 46.9 & $143(27.55)$ & - & & 43.4 & 44.4 \\
\hline Harassing with sexual content ${ }^{\mathrm{a}}$ & 28.9 & & & 9.5 & 35.5 & 23.6 \\
\hline Spreading rumors about one's life $\mathrm{e}^{\mathrm{a}}$ & 59.3 & & & 16.7 & 74.2 & 66 \\
\hline Making fun of someone ${ }^{a}$ & 55.8 & & & 35.7 & 30.8 & 31.2 \\
\hline Insulting $\mathrm{me}^{\mathrm{a}}$ & 73.7 & & & 71.4 & 77.2 & 82.1 \\
\hline $\begin{array}{l}\text { Demonstrating to have information about one's } \\
\text { life that may affect one's psychological well-being }\end{array}$ & 43.4 & & & 59.5 & 73.0 & 82 \\
\hline Revealing data about one's private life $\mathrm{e}^{\mathrm{a}}$ & 33.1 & & & 19.0 & 57.4 & 47.2 \\
\hline Pretending to be someone $\mathrm{b}^{\mathrm{b}}$ & 26.2 & - & $48(9.25)$ & 19.0 & 57.8 & 50 \\
\hline Using someone's image without authorization ${ }^{\mathrm{b}}$ & 17.9 & & & 7.2 & 47.3 & 33 \\
\hline
\end{tabular}

Note: All items are presented in the gerund to represent all perspectives of involvement in cyberbullying.

a Item of intimidation.

b Item of Image appropriation. 
Table 5

Technologies used in victimization/aggression acts.

\begin{tabular}{|c|c|c|c|c|c|c|}
\hline & \multicolumn{2}{|c|}{ Basic education } & \multicolumn{2}{|c|}{ Secondary education } & \multicolumn{2}{|c|}{ Higher education } \\
\hline & Victims & Aggressors & Victims & Aggressors & Victims & Aggressors \\
\hline Computer & 71.1 & 75 & 70 & 75 & 72 & 90.9 \\
\hline Cell phone & 42.1 & 37.5 & 44.3 & 37.5 & 42 & 54.5 \\
\hline Blog & 7.9 & 0 & 8.6 & 12.5 & 20 & 0 \\
\hline Chat & 13.2 & 25 & 14.3 & 12.5 & 14 & 9.1 \\
\hline Email & 10.5 & 12.5 & 17.1 & 12.5 & 14 & 9.1 \\
\hline Facebook & 7.9 & 0 & 25.7 & 29.2 & 58 & 81.8 \\
\hline Hi5 & 39.5 & 25 & 25.7 & 16.7 & 10 & 0 \\
\hline Messenger & 36.8 & 37.5 & 32.9 & 25 & 16 & 27.3 \\
\hline Myspace & 0 & 0 & 0 & 4.2 & 0 & 0 \\
\hline Secondlife & 0 & 0 & 0 & 0 & 0 & 0 \\
\hline SMS/MMS & 42.1 & 25 & 40 & 20.8 & 34 & 54.5 \\
\hline Youtube & 5.3 & 12.5 & 4.3 & 12.5 & 8 & 9.1 \\
\hline
\end{tabular}

Table 6

Coping strategies used by victims

\begin{tabular}{|c|c|c|}
\hline Coping strategies & Acts of intimidation $(N=143)(\%)$ & Acts of image appropriation $(N=48)(\%)$ \\
\hline I changed my profile privacy & 19.6 & 27.1 \\
\hline I deleted my Facebook page & 4.2 & 8.3 \\
\hline I confronted the aggressor & 35.7 & 37.5 \\
\hline I contacted the site manager & 2.8 & 4.2 \\
\hline I contacted the police & 2.8 & 4.2 \\
\hline I stopped answering anonymous calls & 21.7 & 22.9 \\
\hline I closed my email account & 6.3 & 6.3 \\
\hline I avoided contact with the aggressor & 22.4 & 20.8 \\
\hline I excluded the aggressor from my social network & 21.0 & 22.9 \\
\hline I ignored the aggression & 16.1 & 10.4 \\
\hline I changed my mobile number & 10.5 & 14.6 \\
\hline I sought help from someone trustworthy & 6.3 & 6.3 \\
\hline I sought professional support & 3.5 & 6.3 \\
\hline I tried to find out who the aggressor was & 7.7 & 14.6 \\
\hline Paid more attention to my computer's webcam & 2.8 & 4.2 \\
\hline Other & 3.5 & 3.0 \\
\hline
\end{tabular}

Overall, victims of acts of intimidation and image appropriation included as sources of help their friends $(72.7 \%$ and $81.3 \%)$, parents (62.9\% and $70.8 \%$ ), police ( $44.8 \%$ and $41.7 \%$ ), teachers $(28.7 \%$ and $35.4 \%$ ), and classmates (21.7\% and 31.3\%). Despite these high percentages, the fact is that it occurs little in reality, since only $6.3 \%$ of victims reported using the following coping strategy: "sought help of someone trustworthy".

\subsubsection{Aggressors' scale}

The sample in this analysis consisted of $8 \%$ of respondents (42 students) who were aggressors, 59.5\% of which were female aggressors. Their targets were mainly boys (29.3\%) and girls (19.5\%) individually and mixed groups (19.5\%). What's more, these individuals reported that $45 \%$ of the victims were their schoolmates. Hence, there is the same inverted $U$ relationship, as noted earlier in the victims, regarding the level of education the aggressor attended when the cyberbullying was committed. That is, $19 \%$ of the aggressions were committed in primary education, while $57.1 \%$ were carried out in secondary education and $26.2 \%$ in higher education. In terms of the most common aggressions (see Table 4), the following examples illustrate what respondents reported: "I made fun of someone" (71.4\%), "I insulted someone" (59.5\%) and "I pretended to be someone else" (35.7\%).

As for the technology used to perpetrate the aggression, respondents mentioned the computer as the main technology used (71.4\%), then the mobile phone (35.7\%). Facebook (33.3\%), Messenger (26.2\%) and SMS/MMS (26.2\%) prevailed as the preferred digital tools in order to carry out the aggression. As we can see in Table 5 , the use of both computer and cell phones increases from primary to higher education and Facebook and SMS/MMS are the most common technologies used in aggressions in higher education.

The respondents of the aggressor's sub-scale reported that anger (63.6\%), concern (54.4\%) embarrassment (45.5\%), insecurity (36.4\%), fear and sadness (27.3\%) were some of the feelings they believe to have inflicted on their victims. We also analyzed the motives behind the aggressions (see Table 7) and respondents reported mainly that it was: "As revenge regarding past episodes" (54.5\%), "Just for fun" and "Because I didn't like the person's attitudes" (both $36.4 \%$ ).

4.3.3. Observers of victims' scale and observers of aggressors' scale

Many respondents $(45.7 \%)$ reported observing victimization incidents with the majority of acts involving girls individually

Table 7

Motives aggressors mentioned for cyberbullying others.

\begin{tabular}{lr}
\hline Motives & $\%$ \\
\hline For the group to accept me & 0.0 \\
Just for fun & 36.4 \\
For not being able to be personally affirmative to the person & 9.1 \\
For revenge regarding past episodes & 54.5 \\
Because I wanted to assert myself & 18.2 \\
Because the person fits those stereotypes usually mocked & 9.1 \\
Because the person has a strange personality & 9.1 \\
Because I don't like the person's attitudes & 36.4 \\
Because there's no problem acting this way & 9.1 \\
Because he belongs to a rival group & 27.3 \\
Because if someone abuses me, I can also abuse & 27.3 \\
Other & 27.3 \\
\hline
\end{tabular}


(47.4\%), followed by mixed groups (19.4\%) and boys individually (12.1\%). The number of the aggressors' observers was lower (20.4\%) because cyberbullying is a phenomenon that allows aggressors to remain anonymous (Slonje \& Smith, 2008). The aggressors were mostly observed in the act of cyberbullying in mixed groups (26\%), followed by a single girl situation (25\%), a single boy situation (20\%) and in a group of girls (12\%). The victims' observers reported that the last aggression they observed occurred mainly when the victims were attending secondary education (53.6\%), then, higher education (33.2\%), and lastly, primary education $(16.2 \%)$. In terms of the aggressors' observers, the trend reverses slightly, in the sense that the highest percentage was for secondary education (56.2\%), followed by primary education (24.8\%), and lastly, higher education (21.9\%).

According to the acts mentioned by the victims' observers and the aggressors' observers, the most common were: "They made fun of someone" (77.2\% and 82.1\%); "They spread rumors about someone's life" (74.2\% and 66\%) and "They insulted someone" (73\% and $82 \%$ ). Table 4 shows the types of aggressions observed by both types of observers.

Many of the victims' observers (54.6\%) tried to prevent the continuation of aggressions and the main coping strategies reported were "I tried to support the victim" (44.5\%), followed by "I tried to understand the gravity of the situation" (24.2\%) and "I advised the victim to tell someone trustworthy" (21.6\%). A smaller percentage of the aggressors' observers (49\%) tried to prevent the situation, and the preferred coping strategies were "Prevent the victim" (20.8\%), "Dissuade the aggressor" (19.8\%), "Denounce the aggressor" (15.1\%).

\subsubsection{Gender, course, school year and age differences}

We found that men revealed a greater tendency towards being victims (Mean Rank $=278.44, U=21,119, p<.05, r=-0.09$ ) and aggressors (Mean Rank $=278.92, U=21,063, p<.01, r=.10$ ). Then, we found significant differences concerning age. Subjects that were 20 years of age or less were more prone to being observers of victims (Mean Rank=277.16), $\chi^{2}(3, N=519)=15.22, \quad p=.01$, $h_{p}{ }^{2}=.03$ and observers of aggressors (Mean Rank=270.54), $\chi^{2}(3, N=519)=9.97, p=.01, h_{p}{ }^{2}=.04$, than other age groups. We found no significant differences in terms of college year (i.e. years 1,2 and 3 of the different courses) regarding reported victims and aggressors. Nonetheless, first year students reported a significantly higher tendency to be the observers of victims (Mean Rank $=274.31), \chi^{2}(2, N=519)=4.97, p=.1, h_{p}{ }^{2}=.01$ and of aggressors (Mean Rank $=276.54), \chi^{2}(2, N=519)=9.29, p=.01, h_{p}{ }^{2}=.02$. What's more, we analyzed courses separately because of the different course cultures. We found significant differences between courses. Specifically, the Social Service students were more prone to being victims (Mean Rank=326.25), $\chi^{2}(6, N=519)=17.72$, $p=.01, h_{p}{ }^{2}=.03$, whereas students from Social Animation were more prone to being aggressors (Mean Rank $=306.88), \chi^{2}(6$, $N=519)=14.11, p=.05, h_{p}^{2}=.03$.

In regards to the strategies used by victims, female students (Mean Rank $=260.86, U=22,771, p=.01, r=.02$ ) and students between the ages of 21 and 23, Mean Rank $=261.50, \chi^{2}(3$, $N=518) 21.65, p<.001, h_{p}^{2}=.04$, were more prone to contacting the site's administration, whereas male students were more inclined towards avoiding the aggressors (Mean Rank $=268.31$, $U=22777, p=.05, r=.05$ ). Also, students enrolled in courses in Education, Journalism and Social Service (Mean Rank $=264.50$ ) tended to deactivate their email, $\chi^{2}(6, N=519) 22.63, p<.001$, $h_{p}{ }^{2}=.04$, whereas only students in Journalism were more prone to exclude the aggressor from their social network, Mean Rank $=275.50, \chi^{2}(6, N=519) 14.14, p<.05, h_{p}{ }^{2}=.03$.

As for the strategies of the observers of victims and aggressors, we found no significant differences in regards to gender, age and course, with the exception of the Science Education students who tried to understand the gravity of the situation as the observers of victims, Mean Rank = 274.00, $\chi^{2}(6, N=518) 11.61, p<.10, h_{p}{ }^{2}=.02$. Nonetheless, we found a small effect size for this difference. Generally, the main coping strategies mentioned by all of the students were: "Block contacts" (64.2\%), "Inform authorities" (63.5\%), "Ask someone you trust for help" (59.1\%), and "Change email accounts" (54.6\%)". They also refer to "Contact site managers" (27.1\%), "Ignore" (25.1\%) and "Create or appeal to a support group" (20.6\%).

As for finding sources of help, the male students were more inclined towards asking parents (Mean Rank $=276.64, U=19,465$, $p=.01, r=.11$ ) and teachers (Mean Rank $=275.93, U=19,543$, $p=.05, r=.11)$ for help than female students. Also, students between the ages of 21 and 23, Mean Rank=260.20, $\chi^{2}(3$, $N=507$ ) $6.54, p<.10, h_{p}{ }^{2}=.10$, were more prone to turn to colleagues for help, whereas students aged 24-26 were more inclined to ask parents, Mean Rank $=298.23, \chi^{2}(3, N=507) 8.27, p<.05$, $h_{p}{ }^{2}=.02$, and teachers, Mean Rank $=284.34, \chi^{2}(3, N=507) 9.83$, $p<.05, h_{p}{ }^{2}=.02$.

Also, students enrolled in courses in Social Service were more prone to turn to parents (Mean Rank $=359.35) \chi^{2}(6, N=508$ ) 31.33, $p<.001, h_{p}{ }^{2}=.06$, and teachers Mean Rank $=356.23, \chi^{2}(6$, $N=508) 41.95, p<.001, h_{p}{ }^{2}=.08$. In general, all respondents were asked about who could help resolve cyberbullying situations and the following were mentioned: friends (73.4\%), parents (72\%), police $(59.1 \%)$, teachers $(43.9 \%)$, responsible by the institution (32.7\%), colleagues (28.1\%) and (6.5\%) other person.

\section{Discussion}

This investigation focused on the incidence of cyberbullying in undergraduate college students with the main objective of understanding this relatively new phenomenon in an understudied population. Cyberbullying has been mainly investigated in adolescence (Kowalski \& Limber, 2007). However, there is the need to verify the impact of this phenomenon in older populations, and to better understand it with the objective of underlining some strategies to prevent it. This investigation also presented the preliminary assessment of the CICS inventory, as an approach of how to measure college students' perceived level and form of involvement in cyberbullying acts. The psychometric data of the present study can be considered as a preliminary study of the CICS. The fact that our results yielded a unidimensional structure of each scale indicates that college students seem to interpret cyberbullying as one only construct, including both direct and indirect forms of aggression. From this preliminary assessment, we concluded that the CICS serves its purpose of providing information about cyberbullying in college students. Thus, the CICS provides a new understanding of how victims, aggressors and observers perceive their level of involvement in cyberbullying.

As a contribution of this investigation, we also aimed to understand the accuracy with which college students reported their level of involvement in acts of cyberbullying. Therefore, unlike most studies involving issues regarding cyberbullying, we used the IRT approach, which enabled us to calibrate our participants and items on a common scale (DeMars, 2010; Embretson, 1996). This type of assessment allowed us to analyze the interactions between our participants and items, which in turn, helped us interpret the variables we wanted to measure. Furthermore, the interpretations of the items in which participants had a higher probability of dominating was convenient for our study, along with other group-related ratings we used later. In order to measure college students' involvement in cyberbullying, and because most of the literature focused on instruments with lower grade levels (e.g. Price \& Dalgleish, 2010), we developed the CICS. Regarding the hypothesis about 
college students' accuracy in reporting their level of involvement in acts of cyberbullying, we feel that the IRT analysis enabled us to interpret the results considering both person and item aspects accurately (DeMars, 2010; Embretson, 1996). Thus, results revealed from the reliability values that the item scores were good. From these results we concluded that this instrument has potential for future use and testing in other higher education contexts where cyberbullying is to be assessed. Also, the item difficulty distribution of the CICS was low in comparison with the students' responses, indicating that the students underrated their involvement in acts of cyberbullying - hence, confirming our hypothesis. This result indicates that one's involvement in acts of cyberbullying is in fact a hidden side of college students, as they do not report it accurately.

On a different note, this research found that $27.94 \%$ of students were victims at some point in their life, compared to a smaller percentage (8\%) of aggressors, as seen in previous studies (Li, 2006, 2008; Dilmaç, 2009; Raskauskas \& Stoltz, 2007). Regarding victimization, analyses were made, considering two different aspects that can be related to characteristics of cyberbullying that are similar to bullying, and to specificities of cyberbullying. Thus, cyberbullying involves acts that are similar to bullying (intimidation) and acts which involve behaviors provided by ICT (image appropriation).

In terms of level of education, respondents reported that the last aggression occurred mainly in secondary education, regardless of the perspective of students, and there were more aggressions experienced, committed and observed in higher education than in primary education, except in relation to the aggressors' observers, who witnessed more aggressions in secondary education than in higher education. This may indicate that despite aggressions being more frequent in higher education; bullies tend to commit theses acts in a more hidden way.

In this study we also found that acts of intimidation (27.55\%) were more frequent than acts of image appropriation $(9.25 \%)$ in higher education, revealing a higher percentage compared to Schenk and Fremouw's study (2012) with college students, where $8.6 \%$ of victims were identified. This result is in accordance with the difficulty the students revealed in the IRT analysis in reporting items involving image appropriation.

In our sample, we found that the largest percentage of victims and aggressors were women, which is consistent with the frequencies found by Kowalski and Limber (2007) and Ortega, Elipe, and Calmaestra (2009) and Ortega, Elipe, Mora-Mérchan, et al. (2009). However, the aggressors from our study report that the victims were generally boys, whereas girls individually and victims report that the most common perpetrators were mixed groups followed by boys individually (Li, 2008). However, we found that girls tend to act in groups, more than boys. Although many victims do not know who their aggressor is, most of the known aggressors are classmates of victims, thus, we can conjure that these acts occur mainly within close and frequent relationships. These results are quite coincident with those of Walker et al. (2011) who verified that approximately $50 \%$ of victims were intimidated by classmates. These results regarding the anonymity of the aggressor are not surprising because this is one of the specificities of cyberbullying (Kowalski \& Limber, 2007). Nonetheless, there is more anonymity involving acts of image appropriation than acts of intimidation, possibly because the first seems more harmful than the last. However, more investigation is necessary.

Regarding the last aggression remembered, we found that acts of image appropriation were lower in higher education and that acts of intimidation were lower in primary education, followed by higher education. The results in the last level of education were superior to those found by Walker et al. (2011) who found $11 \%$ of cyber victims in college. We also found a $U$ inverted relation between the aggressions experienced and the scholar year in which they occurred, with an increase from primary education to secondary education and then a decrease from this last to higher education. In general, the digital media mostly used by victims and perpetrators were SMS/MMS, Facebook, Hi5 and Messenger. These findings are in accordance with other studies (Matos, Vieira, Pessoa, \& Amado, 2013), where cyberbullying was found to be perpetrated through Web pages (e.g. sites such as Youtube and Facebook) on $48 \%$ of victims from basic education and secondary education. Moreover, these victims mentioned that $42 \%$ of these acts were committed by SMS. Nonetheless, the results we present pertain to college students, which could constitute a contribution for this field of study. Furthermore, our results differ from those found by Price and Dalgleish (2010), reporting emails, online chat rooms and social networking sites with approximately $20 \%$ each, followed by Messenger (12\%).

The most common feelings reported by victims were negative (e.g. insecurity, anger, concern, etc). Moreover, the percentages related to feelings were higher in image appropriation than in intimidation, which can be associated with a more harmful consequence of the first. This may be related to the continuum of effects referred by Hinduja and Patchin (2010). In agreement with Matos et al. (2013) the types of aggressions that involve images and videos, as well as phone calls, are perceived by children and adolescents as having a greater impact on their lives. Firstly, the public and potential humiliation of the victim could justify these perceptions. Secondly, telephone calls can have a greater impact in terms of intrusiveness and violation of one's privacy. Nonetheless, more research is needed with regards to types of feelings and acts of aggression. However, it is important to remember that a large percentage of students reported pride $(30.1 \%, 35.4 \%$ for acts of intimidation and image appropriation). That is, the majority of the feelings involved in victimization can be considered negative, with the exception of pride. This result may be related to the attention victims get from the aggressor and observers. So, it would be interesting in further research to understand why victims feel pride in relation to the situation. This may also be related with the same main objectives of digital self-harm or self-cyberbullying. In this case, victims engaged in acts of digital self-harm to attract attention, support, and validation (Englander, 2012), thus victim and perpetrator were the same person.

When cyberbullying situations occur, victims must resort to some type of coping strategies (Smith et al., 2008), such as "Blocking contacts" (64.2\%), "Informing authorities"(63.5\%), "Asking someone trustworthy for help" (59.1\%), and "Changing email accounts" (54.6\%)" as seen in our results. In terms of types of strategies to prevent the continuation of cyberbullying, there are confrontational ("I confronted the offender"), offline avoidance ("I avoided contact with the aggressor") and online coping strategies ("excluding the aggressor from the social network" and "I stopped answering anonymous calls") as Souza (2011) refers. However, our results were much lower than those found by Souza (2011). The implications of our findings in regards to coping strategies are pertinent because considering that cyberbullying is a phenomenon with which adolescents should know how to deal with, it is important to understand which coping strategies are related to it. Nonetheless, college students (as well as younger students) do not always know how to regulate their use of coping strategies. Jacobs et al. (2014) for example, studied the determinants associated with effective and ineffective coping strategies. These authors found that ineffective coping was mostly associated with environmental determinants, followed by psychological determinants, then, to a much lesser extent, personal and behavioral determinants, and, lastly, social demographic determinants (i.e. younger age). As we have seen in this study, there were different types of strategies used on behalf of the different participants in acts of cyberbullying. There are technological strategies that are used to stop aggression, aggressive coping strategies (e.g. a cybervictim becoming a cyberbully), passive strategies (e.g. 
doing nothing), cognitive strategies (e.g. talking to the aggressor) and social strategies, such as asking for help from someone trustworthy (Matos et al., 2013).

In this study, most of the victims' observers (44.5\%) took on a support position ("I supported the victim"), while the aggressors' observers took on two distinct positions: prevention ("Preventing the victim", 20.8\%) and combating the situation ("Dissuade the aggressor"', 19.8\%). The discrepancy between the percentages of "who can help the victim" $(72.7 \%$ and $81.3 \%$ regarding friends and $62.9 \%$ and $70.8 \%$ regarding parents, in acts of intimidation and image appropriation) suggests that victims felt better understood by friends. Beyond that, teachers were more referred to than classmates, suggesting that the first were considered more capable of dealing with this type of situations, probably because of their experience with people. Comparing these discrepancies to what actually occurs ("sought help of someone trustworthy"; $6.3 \%$ of victims), our results differed greatly from those of Walker et al. (2011), where $71 \%$ of students reported having told their parents or another adult about the incident. This is particularly worrying because it may indicate college students' will maintain acts of cyberbullying as low profile incidents. An explanation for the discrepancy between "who can help" and the actual request for help, may be that although victims consider that someone can help, something prevents them from asking for help. For example, as mentioned in the literature, victims may think that adults are not aware of cyberbullying situations (Slonje \& Smith, 2008), fearing that telling might not be effective (Price \& Dalgleish, 2010). Moreover, victims may fear that they might be deprived of these technologies (Beran \& Li, 2007; Campbell, 2005), and may also feel humiliated and embarrassed. Furthermore, they may also worry about whether the incident will be trivialized by adults, or even whether someone makes them feel responsible for what is happening (Campbell, 2005). Nonetheless, friends and parents were still considered the most reliable people to help (Pettalia, Levin, \& Dickinson, 2013).

Aggressors most frequently "made fun of someone", "insulted someone" and then, "pretended to be someone else". The first two types of aggression correspond to two of the most common acts reported by victims. The latter was less referred to by victims, possibly because they might have not realized the exchange of identities at the time. This result is also in accordance with the IRT analysis, where results indicated that students had difficulty in responding to this item.

Most aggressors explained that their actions were "For revenge regarding past episodes" (54.5\%) as found in this study and may be related to the continuity between bullying and cyberbullying mentioned by participants in the interviews - the bullied become the cyberbullies. In accordance with our findings, Akbulut and Eristi (2011) found that approximately 25\% of the aggressors reported similar reasons: "To get revenge" and "Having previously been a cybervictim". Furthermore, Schenk, Fremouw, and Keelan (2013) found that half of the aggressors reported "anger" and $17.6 \%$ "revenge". Therefore, these actions can be associated with retaliation of victimization from bullying and /or cyberbullying (Akbulut \& Eristi, 2011; Slonje \& Smith, 2008). Thus, a bullying victim at school may try to retaliate online (Beran \& Li, 2007; Willard, 2005). This can be related with one of the motives referred by the respondents, namely "For revenge regarding past episodes". Souza (2011) studied the perspectives of 118 first year students enrolled in a Psychology course who mentioned some reasons for cyberbullying, such as the need for acceptance (5.0\%); revenge (2.5\%) and self-assertion (8.4\%). There is nonetheless, a large discrepancy between Souza's study (2011) and the present data, namely because the motives in the previous study were not given by the aggressors themselves, but by other students trying to guess the aggressor's motives.
Another motive was "Just for fun" (36.4\%) as previously mentioned by Smith et al. (2008), which may relate to the fact that they are not aware of the consequences of experiencing cyberbullying (Hinduja \& Patchin, 2009). Other motives found in Schenk et al. (2013), included "dislike" and "hatred" (both with 38.2\%) which may be linked to the motive "Because I don't like the person's attitudes" (36.4\%) found in our study. Through focus group interviews, Smith et al. (2008) presented other motives for cyberbullying. Some of the motives included: “... Do not have to meet personally", "There is less fear of being caught" and "people are too afraid to do things face-to-face". Finally, in our data one of the most mentioned motives was "Because I don't like the person's attitudes" (36.4\%), which could be related to the last motive referred to by Smith et al. (2008). It may reveal some interpersonal difficulties people have in their relationships or difficulty in being assertive, which may lead people to act in anonymity.

Considering the two types of observers, we found a large discrepancy between those who observe the victimization (45.7\%) and those who observe the aggression (20.4\%). This discrepancy may be due to the nature of cyberbullying, since it allows aggressors to remain anonymous (Slonje \& Smith, 2008). What's more, a possible explanation for this is because aggressors intend to be observed. Nonetheless, aggressors have just some measure of anonymity due to their "digital footprint" (Hinduja \& Patchin, 2009).

Observers are a very important part of cyberbullying resolutions, and this can begin with their own attitude towards cyberbullying. The observer's role differs greatly depending on the severity of the incident, as indicated by Bastiaensens et al. (2014). These authors found that participants who were exposed to the more severe harassing incident, had significantly higher behavioral intentions to help the victim. On the other hand, when the cyberbullying incident was considered less severe, observers could perceive a smaller opportunity to gain social rewards. Additionally, the presence of other bystanders could cause a perceived risk for negative social evaluation when helping (Bastiaensens et al., 2014).

In our study, victims' observers revealed a less proactive form of dealing with the aggressions, focusing on supporting the victim and understanding the gravity of the situation. Similarly to results found by Li (2006) most observers did not report the incident, as we also verified in our IRT analysis. These less proactive attitudes may have occurred because they could not control the behavior of the aggressor.

Nonetheless, aggressors' observers seem to have a privileged role in preventing these situations because they know who the aggressor is and may act directly on his/her behavior. One of the strategies we found that was used was "Denounce the aggressor" (15.1\%), which differs in terms of percentage from the results obtained by Li (2007) in which $34.5 \%$ of observers told the episode to an adult. However, this difference may be related to the fact that this author worked with younger subjects (7th grade). Thus, we believe that younger victims tend to feel more comfortable in asking for help, whereas university students may think that asking for help can be a sign of weakness, because they are older and more independent from parental influences (Schenk \& Fremouw, 2012). Tokunaga (2010) referred that telling parents may be considered a "childish behavior", which may explain the reduced amount of students that tell their parents about acts of cyberbullying. What's more, our results from the IRT indicate that college students underrated their involvement in acts of cyberbullying, whether it was from the perspective of the victim, the aggressor or one of the observers. Hence, if college students have difficulty in reporting this involvement, it is also likely that they have difficulty in telling others. Moreover, according to Slonje and Smith (2008), students consider that adults are less aware of bullying via SMS, email and phone calls, than of traditional bullying. Hence, considering the possible negative effects and consequences of 
bullying (i.e. cyberbullying), such as decreased academic performance (Juvonen, Wang, \& Espinoza, 2011; Strøm et al., 2013), dropping out of school (Jordan, McPartland, \& Lara, 1999; Jozefowicz-Simbeni, 2008), anxiety and depression (Anthony, Wessler, \& Sebian, 2010), suicidal or homicidal ideation and action (Duke, Pettingell, McMorris, \& Borowsky, 2010; Fleming \& Jacobsen, 2010), and knowing that college students underrate their involvement in cyberbullying and that they do not ask for help as much as they probably should, could lead further research to study how to get these students to be more aware and more open about these occurrences. These results are thus pertinent and have important implications for the development of new studies involving prevention and awareness programs against cyberbullying because they lead towards a better understanding of how there is still much work to be done in getting college students to face these situations.

Although adults were referred to as being someone who can help (related to "Ask someone you trust for help": 59.1\%), students may have considered that they were unaware of this problem, and therefore, would not rely on their support (6.3\% of victims reported using the following coping strategy: "sought help from someone trustworthy."). According to Slonje and Smith (2008), strategies depend on the type of aggression and the means used to commit cyberbullying, because some aggressions are easier to keep as evidence in order to ask for help (eg. email and SMS), which allows adults to take appropriate actions regarding the aggression.

This study also revealed some interesting findings about differences in cyberbullying regarding gender, age, course, and school year. Specifically, male students were more prone to being aggressors, which is consistent with Dilmaç (2009) and Li (2006), but contrary to the findings reported by Smith et al. (2008), where female students were considered to be more associated with cyberbullying. Moreover, male students were also more prone to being victims, which is the opposite of the results found by Dilmaç (2009). As for the courses analyzed, the Social Service students were more prone to being victims, whereas students from Social Animation were more prone to being aggressors. What's more, subjects that were 20 years of age or less, and those who attended the first year of college were more prone to being observers of victims and observers of aggressors.

In terms of strategies used by victims, female students between the ages of 21 and 23 were more prone to using online coping strategies, whereas male students were more inclined to use offline avoidance coping strategies. Furthermore, students enrolled in courses in Education, Journalism and Social Service tended to use online coping strategies, such as, deactivate the email, and students in Journalism tended to use another one, exclude the aggressor from the social network.

Considering that observers have a fundamental role in stopping and preventing cyberbullying situations, it is worrying that just a small percentage of observers of victims advises the victim to tell someone trustworthy; and that the observers of aggressors take a passive role, with few observers dissuading and denouncing the aggressor. What's more, it is interesting to observe that parents and teachers are considered the major sources of help, however, few are the cases in which students actually ask for help. This, along with the relatively passive role of observers, creates the need to rapidly intervene in the preconceived idea that cyberbullying is harmless.

\subsection{Limitations and future research}

The instrument used provided information about the last experience remembered but it does not contemplate a possible continuity between being a victim or being an aggressor in primary and/or high school and later in college. Therefore, it would be interesting to assess cyberbullying in college settings contemplating a longitudinal methodology. Additionally, we used a self-report instrument, therefore, false reporting and social desirability could be a limitation. To better understand cyberbullying in college settings, it would also be enriching to conduct a deeper analysis of cyberbullying by using interviews from different courses and with larger samples. Also, our sample did not allow us to perform post-hoc tests after the Kruskal-Wallis test. Hence, future research could focus on gathering a larger sample size with which these tests could be performed. Furthermore, the inventory presented in this study could be tested in the future with Structural Equation Modeling. Further research could also gather objective data (e.g. screen recordings) to complement the data from the CICS in different academic levels and test for between and within-group variations with multilevel analysis. Another interesting subject for future research is to study how emotional regulation can be worked in order to decrease cyberbullying acts, and to strengthen coping strategies in victims. Furthermore, it would be interesting to study how students themselves, can work along the community to prevent or deal with cyberbullying.

\section{Implications and conclusions}

This study presented an instrument that has the potential to assess cyberbullying in higher education contexts. Furthermore, the analyses made with the CICS helped us understand how college students perceive cyberbullying. Specifically, we found that students underrated their involvement in acts of cyberbullying, which indicates that one's involvement in acts of cyberbullying is in fact, a hidden side of college students. So as to fight cyberbullying there needs to be systemic and conjugated intervention (Souza, 2011), involving students, professionals and the academic institution. Cyberbullying prevention may be incorporated in anti-bullying programs comprising a whole-school anti-bullying policy, awareness-raising and curriculum-based activities (Slonje et al., 2013).

Some considerations about cyberbullying prevention and intervention are possible. Firstly, an intervention in academic institutions should alert students to the dangers of the malicious use of technology. The institution may do so by giving lectures/workshops about this topic, and by distributing pamphlets and placing posters alerting for this danger. Secondly, we identified an inaccurate vision of the level of involvement in acts of cyberbullying and potential misuse of ICT. Thus, students should become more aware of what risks they are taking when they are literally living in a social networked world. Thirdly, there is a need to strengthen bonds in the real world, by making more meaningful commitments in real-life relationships. Through bonds of trust, individuals may learn to confide more in others.

Considering observers have a great importance in preventing cyberbullying, such as in bullying (Bastiaensens et al., 2014), students should be taught about the psychological and physical signs of being victims or aggressors. Once this has been implemented, students may be able to detect these events, and help in their resolution, being this considered an intervention focused on the problem (Souza, 2011; Souza, Veiga Simão, \& Caetano, 2014). This help may be directly given to the victim or the aggressor, but may also be indirect by contacting other people to help (parents, teachers, psychologists, institution, etc.). Since differences have been found in relation to gender in the behavioral intentions to help victims (Bastiaensens et al., 2014), interventions for observers should attend to gender.

The implications of this study are relevant for the area of Internet safety in schools. The results of this study showed that most students did not report a very proactive role in cyberbullying events. Hence, it seems imperative for research and practice to focus on educational programs that are systematic in teaching 
students about security strategies in order to prevent the emergence of cyberbullying. Educational psychologists for example, could be involved in these programs with ICT specialists to form multidisciplinary teams. Specifically, these professionals could support students in understanding why they take so many risks in the technological world, and from there, find answers that meet these students' needs by providing guidance. Also, professionals of the area could also invest in developing healthy attitudes in students and their parents towards ICT from early on. Moreover, these professionals could work towards educating students with information and skills that help them respond effectively to cyberbullying situations (Sabella, Patchin, \& Hinduja, 2013). This strategy could also be applied to parents, in terms of prevention and intervention. Furthermore, learning from children and young people can be an effective way to achieve parents knowledge on ICT - parents can be encouraged to let their children be the "experts" and help them understand the tools that they are using online. In this sense, we should develop children's skills (Iudici, 2013). In addition, parents should proactively and regularly access cybersafety resources designed for them, with the purpose of becoming more familiar with emerging technologies and online trends (Faccio, Iudici, Costa, \& Belloni, 2014).

Cybermentoring (Slonje et al., 2013) may be a good strategy for obtaining support, but may also be a useful method to learn more about technologies and cyberspace safety. Thus, through the use of ICT, victims may become more aware of their risks but can also receive support without their identity being known. Furthermore, peer helper programs may take place to educate students about using technology responsibly (Sabella et al., 2013). In the CyberMentors program for instance, students are trained as cybermentors, log on and mentor on demand, and they can refer mentees onto senior cybermentors and counselors for further support if necessary (Faccio et al., 2014).

It is important to remember that all students have their place in interventions, starting with victims, aggressors and observers, because all of them have to deal with cyberbullying. Providing students, teachers, and parents with more information and increasing their awareness of these issues can help prevent cyberbullying (Jang et al., 2014). The issue of adult awareness is crucial when it comes to effective action by schools against cyberbullying. This is important since pupil's perception may influence their behavior on asking for help. If students perceive adults to be unaware of cyberbullying, they may not tend to go to them in order to receive support (Faccio et al., 2014).

Hence, the academic community should organize activities to discuss cyberbullying, like role plays, debates, and plays. Structured intervention programs should cover socio-emotional skills, and focus primarily on empathy and assertiveness, but keeping in mind that all of these interpersonal skills are transversal to a healthy socio-emotional development. Only with these interdisciplinary efforts can cyberbullying emerge from a hidden phenomenon to an overt occurrence, where victimization and aggression can decrease and observation, awareness and guidance develop. Ultimately, we feel that this study has made its contribution to research and practice in helping professionals become aware of the overt and covert dynamics of cyberbullying in college students. Thus, with this type of knowledge professionals are equipped with tools to help college students change their "profile" to a cyberbullying free profile, where there's no place for the hidden side of cyberbullying.

\section{Acknowledgement}

We would like to thank to the research team of the project Cyberbullying: A diagnosis of the situation in Portugal.

\section{References}

Akbulut, Y., \& Eristi, B. (2011). Cyberbullying and victimisation among Turkish university students. Australasian Journal of Educational Technology, 27(7), 1155-1170. <http://www.ascilite.org.au/ajet/ajet27/akbulut.pdf>.

Amado, J., Matos, A., Pessoa, T., \& Jäger, T. (2009). Cyberbullying: Um desafio à investigação e à formação. Interacções, 5(13), 301-326. <http://repositorio. ipsantarem.pt/handle/10400.15/360>.

Anderson, T., \& Sturm, B. (2007). Cyberbullying from playground to computer Young Adult Library Services, 5(2), 24-27.

Anthony, B., Wessler, S., \& Sebian, J. (2010). Commentary: Guiding a public health approach to bullying. Journal of Pediatric Psychology, 35(10), 1113-1115. http:// dx.doi.org/10.1093/jpepsy/jsq083.

Azevedo, P. (2013). Cyberbullying em estudantes do ensino superior politécnico (Cyberbullying among students of the polytechnic). Masters thesis. School of Education of Polytechnic Institute of Portalegre, Portugal.

Bandalos, D. L. \& Finney, S. J. (2010). Exploratory and confirmatory factor analysis. In G. R. Hancock \& R. O. Mueller (Eds.), Quantitative methods in the social and behavioral sciences: A guide for researchers and reviewers. New York: Routledge.

Baroncelli, A., \& Ciucci, E. (2014). Unique effects of different components of trait emotional intelligence in traditional bullying and cyberbullying. Journal of Adolescence, 37, 807-815. <http://dx.doi.org/10.1016/j.adolescence.2014.05.009>.

Bastiaensens, S., Vandebosch, H., Poels, K., Van Cleemput, K., DeSmet, A., \& De Bourdeaudhuij, D. (2014). Cyberbullying on social network sites. An experimental study into bystanders' behavioural intentions to help the victim or reinforce the bully. Computers in Human Behavior, 31, 259-271. http:// dx.doi.org/10.1016/j.chb.2013.10.036.

Belsey, B. (2005). Cyberbullying: An emerging threat to the always on generation <http://www.cyberbullying.ca>.

Beran, T. N., \& Li, Q. (2005). Cyber-harassment: A study of a new method for an old behavior. Journal of Educational Computing Research, 32(3), 265-277. http:/| dx.doi.org/10.1177/0829573510396318.

Beran, T., \& Li, Q. (2007). The relationship between cyberbullying and schoo bullying. Journal of Student Wellbeing, 1(2), 15-33. <http://www.ojs.unisa. edu.au/index.php/JSW/article/viewFile/172/139>.

Bollen, K. A., \& Long, J. S. (1993). Testing structural equations models. Newbury Park CA: Sage.

Bond, T. G., \& Fox, C. M. (2007). Applying the Rasch model. Mahwah, NJ: Erlbaum.

Brown, T. A. (2006). Confirmatory factor analysis for applied research. New York: The Guilford Press.

Campbell, M. A. (2005). Cyber bullying: An old problem in a new guise? Australian Journal of Guidance and Counselling, 15(1), 68-76. http://dx.doi.org/10.1375/ ajgc.15.1.68.

Clarke, E., \& Kiselica, M. S. (1997). A systemic counseling approach to the problem of bullying. Elementary School Guidance and Counseling, 31(4), 310-326.

David-Ferdon, C., \& Hertz, M. F. (2007). Electronic media, violence, and adolescents: An emerging public health problem. Journal of Adolescent Health, 41(6), S1-S5. http://dx.doi.org/10.1016/j.jadohealth.2007.08.020.

Davis, M. R. (2012). Facebook considers access for 13-and-younger crowd. Education Week, 13. <http://www.edweek.org/ew/articles/2012/06/13/35facebook.h31. html?qs=Facebook>.

DeLara, E. W. (2008). Developing a philosophy about bullying and sexual harassment: Cognitive coping strategies among secondary school students. Journal of School Violence, 7(4), 72-96. http://dx.doi.org/10.1080/1538822 0801973862

DeLara, E. W. (2012). Why adolescents don't disclose incidents of bullying and harassment. Journal of School Violence, 11(4), 288-305. http://dx.doi.org/ 10.1080/15388220.2012.705931.

DeMars, C. (2010). Item response theory. Oxford, UK: Oxford University Press.

Dilmaç, B. (2009). Psychological needs as a predictor of cyber bullying: A preliminary report on college students. Educational Sciences: Theory and Practice, 9(3), 1307-1325. <http://www.eric.ed.gov/PDFS/EJ858926.pdf>.

Dooley, J., Pyżalski, J., \& Cross, D. (2009). Cyberbullying versus face-to-face bullying: A theoretical and conceptual review. Zeitschrift für Psychologie/Journal of Psychology, 217(4), 182-188. http://dx.doi.org/10.1027/0044-3409.217.4.182.

Duke, N. N., Pettingell, S. L., McMorris, B. J., \& Borowsky, I. W. (2010). Adolescent violence perpetration: Associations with multiple types of adverse childhood experiences. Pediatrics, 125(4), 778-786. http://dx.doi.org/10.1542/peds.20090597.

Ellison, N., \& Boyd, D. (2013). Sociality through social network sites. In W. Dutton (Ed.), The oxford handbook of internet studies (pp. 151-172). Oxford: Oxford University Press.

Embretson, S. E. (1996). Item response theory models and inferential bias in multiple group comparisons. Applied Psychological Measurement, 20, 201-212. http://dx.doi.org/10.1037/1040-3590.8.4.341.

Englander, E. (2012). Digital self-harm: Frequency, type, motivations, and outcomes. In Massachusetts aggression reduction center research reports (Vol. 5) $<$ http://vc.bridgew.edu/marc_reports/5/>.

Espelage, D., \& Swearer, S. (2003). Research on school bullying and victimization: What have we learned and where do we go from here? School Psychology Review, 32(3), 365-383. <http://espelageagainstbullying.com/images/pdf/ Espelage,\%20D.\%20L.,\%20\&\%20Swearer,\%20S.\%20M.\%20\%282003\%29.pdf>.

Faccio, E., Iudici, A., Costa, N., \& Belloni, E. (2014). Cyberbullying and interventions programs in school and clinical setting. Procedia - Social and Behavioral Sciences, 122, 500-505. http://dx.doi.org/10.1016/j.sbspro.2014.01.1382. 
Ferreira, A. I., Almeida, L., \& Prieto, G. (2011). The role of processes and contents in human memory: An item response theory approach. Journal of Cognitive Psychology, 23(7), 873-885. http://dx.doi.org/10.1080/20445911.2011.584692.

Ferreira, A. I., Almeida, L., \& Prieto, G. (2012). Construction of a memory battery for computerized administration, using item response theory. Psychological Reports, 111(2), 585-609. http://dx.doi.org/10.2466/03.04.PR0.111.5.585-609.

Finn, J. (2004). A survey of online harassment at a university campus. Journal of Interpersonal Violence, 19(4), 468-483. http://dx.doi.org/10.1177/088626050 3262083.

Fleming, L. C., \& Jacobsen, K. H. (2010). Bullying among middle-school students in low and middle income countries. Health Promotion International, 25(1), 73-84. http://dx.doi.org/10.1093/heapro/dap046.

Ford, J. K., MacCallum, R. C., \& Tait, M. (1986). The application of exploratory factor analysis in applied psychology: Critical review and analysis. Personne Psychologist, 39(2), 292-314.

Fox, C. M., \& Jones, J. A. (1998). Uses of Rasch modeling in counseling psychology research. Journal of Counseling Psychology, 45(1), 30-45. http://dx.doi.org/ 10.1037/0022-0167.45.1.30.

Francisco, S. M. (2012). Cyberbullying: A faceta de um fenómeno em jovens universitários portugueses (Cyberbullying: The facet of a phenomenon in Portuguese university students). Masters thesis. Faculty de Psychology of University of Lisbon, Lisbon, Portugal.

Garbarino, J., \& DeLara, E. (2002). And words can hurt forever: How to protect adolescents from bullying, harassment, and emotional violence. New York, NY: Simon \& Schuster/The Free Press.

Glover, D., Gough, G., Johnson, M., \& Cartwright, N. (2000). Bullying in 25 secondary schools: Incidence, impact and intervention. Educational Research, 42(2), 141-156. http://dx.doi.org/10.1080/001318800363782.

Gradinger, P., Strohmeier, D., \& Spiel, C. (2010). Definition and measurement of cyberbullying. Cyberpsychology: Journal of Psychosocial Research on Cyberspace, 4(2), 1-13. <http://cyberpsychology.eu/view.php? cisloclanku=2010112301>.

Graham, S., Bellmore, A., \& Juvonen, J. (2003). Peer victimization in middle school When self- and peer views diverge. Journal of Applied School Psychology, 19(2), 117-138. http://dx.doi.org/10.1300/J008v19n02_08.

Hinduja, S., \& Patchin, J. (2009). Bullying beyond the schoolyard: Preventing and responding to cyberbullying. Thousand Oaks, CA: Sage Publications. ISBN:978141 296689.

Hinduja, S., \& Patchin, J. (2010). Bullying, cyberbullying, and suicide. Archives of Suicide Research, 14(3), 206-221. http://dx.doi.org/10.1080/13811118.2010. 494133.

Iudici, A. (2013). Skills-lab project - Promoting the integration of diversity as a culture of participation. Community relief, economic, social, clinical and health. Procedia - Social Behavioral Sciences, 126, 3636-3640. http://dx.doi.org/10.1016/ j.sbspro.01.815.

Jacobs, N. C. L., Dehue, F., Völlink, T., \& Lechner, L. (2014). Determinants of adolescents' ineffective and improved coping with cyberbullying: A Delphi study. Journal of Adolescence, 37, 373-385. http://dx.doi.org/10.1016 j.adolescence.2014.02.011.

Jang, H., Song, J., \& Kim, R. (2014). Does the offline bully-victimization influence cyberbullying behavior among youths? Application of general strain theory. Computers in Human Behavior, 31(1), 85-93.

Jordan, W. J., McPartland, J. M., \& Lara, J. (1999). Rethinking the causes of high school dropout. The Prevention Researcher, 6(3), 1-12.

Joreskog K. G. (1977). Factor analysis by least-squares and maximum-likelihood methods. In K. Enslein, A. Ralston, \& H. S. Wilf (Eds.), Statistical methods for digital computers (pp. 125-153). New York: Wiley.

Jozefowicz-Simbeni, D. M. H. (2008). An ecological and developmental perspective on dropout risk factors in early adolescence: Role of school social workers in dropout prevention efforts. Children and Schools, 30(1), 49-62. http://dx.doi.org/ 10.1093/cs/30.1.49

Juvonen, J., Wang, Y., \& Espinoza, G. (2011). Bullying experiences and compromise academic performance across middle school grades. The Journal of Early Adolescence, 31(1), 152-173. http://dx.doi.org/10.1177/0272431610379415.

Kowalski, R., \& Limber, S. (2007). Electronic bullying among middle school students. Journal of Adolescent Health, 41(S6), 22-30. http://dx.doi.org/10.1016/j. jadohealth.2007.08.017

Kraft, E., \& Wang, J. (2010). An exploratory study of the cyberbullying and cyberstalking experiences and factors related to victimization of students at a public liberal arts college. International Journal of Technologies, 1(4), 74-91. http://dx.doi.org/10.4018/jte.2010100106.

Langos, C. (2013). Cyberbullying, associated harm and the criminal law. Doctora thesis. University of South Australia, Adelaide, South Australia <http:/ arrow.unisa.edu.au:8081/1959.8/151636>

Langos, C. (2014). Cyberbullying: The shades of harm. Psychiatry, Psychology and Law, 1-18. http://dx.doi.org/10.1080/13218719.2014.919643.

Li, Q. (2006). Cyberbullying in schools: A research of gender differences. School Psychology International, 27(2), 157-170. http://dx.doi.org/10.1177/ 01430343060.

Li, Q. (2007). New bottle but old wine: A research of cyberbullying in schools. Computers in Human Behavior, 23(4), 1777-1791. http://dx.doi.org/10.1016/ j.chb.2005.10.005.

Li, Q. (2008). A cross-cultural comparison of adolescents' experiences related to cyberbullying. Educational Research, 50(3), 223-234. http://dx.doi.org/10.1080/ 00131880802309333.

Matos, A., Vieira, C., Pessoa, T., \& Amado, J. (2013). O Cyberbullying nas escola portuguesas: Um desafio à promoção da literacia mediática (Cyberbulliyng in
Portuguese schools: A challenge to promote media literacy). In S. G. Silva \& S. Pereira (Coords.), Conference proceedings from the 2nd literacy congress, media and citizenship (pp. 378-394). Lisbon: Cabinet of Social Communication Sources - Research group on Media Literacy <http://iteraciamediatica.pt/congresso/ atas-do-congresso-versao-integral>.

McDonald, R. P. (1999). Test theory: A unified treatment. Mahwah, NJ: LEA

Mishna, F., \& Alaggio, R. (2005). Weighing the risks: A child's decision to disclose peer victimization. Children and Schools, 27(4), 217-226. http://dx.doi.org/ $10.1093 / \mathrm{cs} / 27.4 .217$.

Muthén, B., \& Kaplan, D. (1985). A comparison of some methodologies for the factor analysis of non-normal Likert variables. British Journal of Mathematical and Statistical Psychology, 38(2), 171-189. http://dx.doi.org/10.1111/j.2044-8317. 1985.tb00832.x.

Muthén, B., \& Kaplan, D. (1992). A comparison of some methodologies for the factor analysis of non-normal Likert variables: A note on the size of the model. British Journal of Mathematical and Statistical Psychology, 45(1), 19-30. http:/ dx.doi.org/10.1111/j.2044-8317.1992.tb00975.x.

Nunnally, J. C. (1978). Psychometric theory (2nd ed.). New York: McGraw-Hill.

Olweus, D. (1993). Bullying in school: What we know and what we can do. Oxford: Blackwell.

Ortega, R., Elipe, P., \& Calmaestra, J. (2009). Emociones de agressores y víctimas de cyberbullying: Un estúdio preliminar en estudantes de secundaria. Ansiedad y Estrés, 15(2-3), 151-165 <http://web.ebscohost.com/ehost/pdfviewer/pdfviewer? vid=3\&sid=7a8c14d8-6e86-420c-b90a-50b9debc00a1\%40sessionmgr15\&hid=21>.

Ortega, R., Elipe, P., Mora-Mérchan, J. A., Calmaestra, J., \& Vega, E. (2009). The emotional impact on victims of traditional bullying and cyberbullying: A study of Spanish adolescents. Zeitschrift für Psychologie/Journal of Psychology, 217(4), 197-204. http://dx.doi.org/10.1027/0044-3409.217.4.197.

Pepler, D., Jiang, D., Craig, W., \& Connolly, J. (2008). Developmental trajectories of bullying and associated factors. Child Development, 79(2), 325-338. http:// dx.doi.org/10.1111/ j.1467-8624.2007.01128.x.

Pettalia, J. L., Levin, E., \& Dickinson, J. (2013). Cyberbullying: Eliciting harm without consequence. Computers in Human Behavior, 29(6), 2758-2765.

Price, M., \& Dalgleish, J. (2010). Cyberbullying: Experiences, impact and coping strategies as described by Australian young people. Youth Studies Australia, 29(2), 51-59. <http://web.ebscohost.com/ehost/pdfviewer/pdfviewer?vid=3\&sid=07d0 fcac-c053-482d-b497-9a6c3c66c287\%40sessionmgr12\&hid=21>.

Rasch, G. (1980). Probabilistic models for some intelligence and attainment tests. Chicago, IL: University of Chicago Press (Original work published 1960).

Raskauskas, J., \& Stoltz, A. D. (2007). Involvement in traditional and electronic bullying among adolescents. Developmental Psychology, 43(3), 564-575. http:// dx.doi.org/10.1037/0012-1649.43.3.564.

Roland, E. (2002). Bullying, depressive symptoms and suicidal thoughts. Educational Research, 44(1), 55-67. http://dx.doi.org/10.1080/00131880110107351.

Sabella, R. A., Patchin, J. W., \& Hinduja, S. (2013). Cyberbullying myths and realities. Computers in Human Behavior, 29(6), 2703-2711. http://dx.doi.org/10.1016/j. chb.2013.06.040.

Schenk, A. M., \& Fremouw, W. J. (2012). Prevalence, psychological impact, and coping of cyberbully victims among college students. Journal of School Violence, 11(1), 21-37. http://dx.doi.org/10.1080/15388220.2011.630310.

Schenk, A. M., Fremouw, W. J., \& Keelan, C. M. (2013). Characteristics of college cyberbullies. Computers in Human Behavior, 29(6), 2320-2327. http://dx.doi.org/ 10.1016/j.chb.2013.05.013.

Slonje, R., \& Smith, P. K. (2008). Cyberbullying: Another main type of bullying? Scandinavian Journal of Psychology, 49(2), 147-154. http://dx.doi.org/10.1111/ j.1467-9450.2007.00611.x.

Slonje, R., Smith, P. K., \& Frisén, A. (2013). The nature of cyberbullying, and strategies for prevention. Computers in Human Behavior, 29(1), 26-32. http:// dx.doi.org/10.1016/j.chb.2012.05.024.

Smith, E. V. Jr., (2001). Evidence for the reliability of measures and validity of measure interpretation: A Rasch measure perspective. Journal of Applied Measurement, 2(3), 281-311.

Smith, P. K., \& Brain, P. (2000). Bullying in schools: Lessons from two decades of research. Aggressive Behavior, 26(1), 1-9. http://dx.doi.org/10.1002/(SICI)10982337(2000) 26:1<1::AID-AB1>3.0.CO:2-7.

Smith, P. K., Mahdavi, J., Carvalho, M., Fisher, S., Russell, S., \& Tippett, N. (2008). Cyberbullying: Its nature and impact in secondary school pupils. Journal of Child Psychology and Psychiatry, 49(4), 376-385. http://dx.doi.org/10.1111/j.14697610.2007.01846.x.

Souza, S. B. (2011). Cyberbullying: Estudo exploratório sobre as perspectivas acerca do fenómeno e das estratégias de enfrentamento com jovens universitários portugueses (Exploratory study about the perspectives of young Portuguese university students regarding the phenomenon and coping strategies). Masters thesis. Faculty de Psychology of University of Lisbon, Lisbon, Portugal.

Souza, S. B., Veiga Simão, A. M., \& Caetano, A. (2014). Cyberbullying: Perspectivas acerca do Fenômeno e das Estratégias de Enfrentamento (Cyberbullying: Perspectives about the phenomenon and coping strategies). Psicologia: Reflexão e Crítica, 27(3). http://www.redalyc.org/pdf/188/18831844020.pdf.

Spears, B., Slee, P., Owens, L., \& Johnson, B. (2009). Behind the scenes and screens: Insights into the human dimension of covert and cyberbullying. Zeitschrift für Psychologie/Journal of Psychology, 217(4), 189-196. http://dx.doi.org/10.1027/ 0044-3409.217.4.189.

Strøm, I. F., Thoresen, S., Wentzel-Larsen, T., \& Dyb, G. (2013). Violence, bullying and academic achievement: A study of 15-year-old adolescents and their school environment. Child Abuse and Neglect, 37, 243-251. http://dx.doi.org/10.1016/ j.chiabu.2012.10.010. 
Talwar, V., Gomez-Garibello, C., \& Shariff, S. (2014). Adolescents' moral evaluations and ratings of cyberbullying: The effect of veracity and intentionality behind the event. Computers in Human Behavior, 36, 122-128. http://dx.doi.org/ 10.1016/j.chb.2014.03. 046.

Tokunaga, R. S. (2010). Following you home from school: A critical review and synthesis of research on cyberbullying victimization. Computers in Human Behaviour, 26, 277-287.

Vannucci, M., Nocentini, A., Mazzoni, G., \& Menesini, E. (2012). Recalling unpresented hostile words: False memories predictors of traditional and cyberbullying. European Journal of Developmental Psychology, 9(2), 182-194.

Velicer, W. F. (1976). Determining the number of components from the matrix of partial correlations. Psychometrika, 41(3), 321-327. http://dx.doi.org/10.1007/ BF02293557.

Walker, C. M., Sockman, B. R., \& Koehn, S. (2011). An exploratory study of cyberbullying with undergraduate university students. Tech Trends, 55(2), 31-38. http://dx.doi.org/10.1007/s11528-011-0481-0.
Willard, N. (2005). Educators guide to cyberbullying and cyberthreats <http:// new.csriu.org/cyberbully/docs/cbteducator.pdf>

Williams, K., \& Guerra, N. (2007). Prevalence and predictors of internet bullying Journal of Adolescent Health, 41(6), S14-S21. http://dx.doi.org/10.1016 j.jadohealth.2007.08.018.

Wolak, J., Mitchell, K. J., \& Finkelhor, D. (2006). Online victimization of youth: Five years later. National Center for Missing \& Exploited Children <http:/ www.unh.edu/ccrc/pdf/CV138.pdf>.

Wright, M. F., \& Li, Y. (2013). Normative beliefs about aggression and cyber aggression among young adults: A longitudinal investigation. Aggressive Behavior, 39, 161-170. http://dx.doi.org/10.1002/ab.21470.

Wright, B. D., \& Masters, G. N. (1982). Rating scale analysis, Chicago, IL: Mesa Press.

Yoon, J., Bauman, S., Choi, T., \& Hutchinson, A. S. (2011). How South Korean teachers handle an incident of school bullying. School Psychology International, 32 312-329. http://dx.doi.org/10.1177/0143034311402311. 